\title{
Cardiopulmonary exercise testing in interstitial lung diseases and the value of ventilatory efficiency
}

\author{
Thomas Gille $e^{1,2}$ and Pierantonio Laveneziana ${ }^{3,4}$
}

\author{
Number 11 in the Series "Ventilatory efficiency and its clinical prognostic value in cardiorespiratory \\ disorders" \\ Edited by Pierantonio Laveneziana and Paolo Palange
}

\begin{abstract}
${ }^{1}$ Université Sorbonne Paris Nord (USPN), INSERM, UMR 1272 Hypoxia \& the Lung, UFR SMBH Léonard de Vinci, Bobigny, France. ${ }^{2}$ Assistance Publique - Hôpitaux de Paris (AP-HP), Groupe Hospitalo-Universitaire Paris-Seine-Saint-Denis (GHUPSSD), Hôpital Avicenne, Service de Physiologie et Explorations Fonctionnelles du Département Médico-Universitaire NARVAL, Bobigny, France. ${ }^{3}$ Sorbonne Université, INSERM, UMRS1158 Neurophysiologie Respiratoire Expérimentale et Clinique, Paris, France. ${ }^{4}$ Assistance Publique - Hôpitaux de Paris (AP-HP), Groupe Hospitalier Universitaire APHP-Sorbonne Université, sites Pitié-Salpêtrière, Saint-Antoine et Tenon, Service des Explorations Fonctionnelles de la Respiration, de l'Exercice et de la Dyspnée (Département R3S), Paris, France.
\end{abstract}

Corresponding author: Thomas Gille (thomas.gille@aphp.fr)

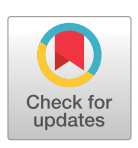

Copyright $\odot$ The authors 2021

This version is distributed under the terms of the Creative Commons Attribution Non-Commercial Licence 4.0. For commercial reproduction rights and permissions contact permissions@ersnet.org

Received: 3 Nov 2020 Accepted: 26 May 2021

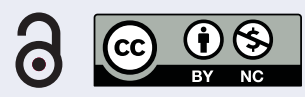

Shareable abstract (@ERSpublications)

Ventilatory inefficiency, as defined by an abnormally increased minute ventilation/carbon dioxide production relationship during cardiopulmonary exercise testing, has diagnostic and prognostic implications in the management of ILDs https://bit.ly/3vFnyhq

Cite this article as: Gille T, Laveneziana P. Cardiopulmonary exercise testing in interstitial lung diseases and the value of ventilatory efficiency. Eur Respir Rev 2021; 30: 200355 [DOI: 10.1183/ 16000617.0355-2020].

Abstract

Interstitial lung diseases (ILDs) are diverse parenchymal pulmonary disorders, primarily characterised by alveolar and interstitial inflammation and/or fibrosis, and sharing pathophysiological similarities. Thus, patients generally harbour common respiratory symptoms, lung function abnormalities and modified exercise adaptation. The most usual and disabling complaint is exertional dyspnoea, frequently responsible for premature exercise interruption. Cardiopulmonary exercise testing (CPET) is increasingly used for the clinical assessment of patients with ILD. This is because exercise performance or dyspnoea on exertion cannot reliably be predicted by resting pulmonary function tests. CPET, therefore, provides an accurate evaluation of functional capacity on an individual basis. CPET can unmask anomalies in the integrated functions of the respiratory, cardiovascular, metabolic, peripheral muscle and neurosensory systems in ILDs. CPET uniquely provides an evaluation of all above aspects and can help clinicians shape ILD patient management. Preliminary evidence suggests that CPET may also generate valuable prognostic information in ILDs and can be used to shed light on the presence of associated pulmonary hypertension. This review aims to provide comprehensive and updated evidence concerning the clinical utility of CPET in ILD patients, with particular focus on the physiological and clinical value of ventilatory efficiency $\left(\dot{V}_{\mathrm{E}} / \dot{V}_{\mathrm{CO}_{2}}\right)$.

Introduction

Interstitial lung diseases (ILDs), formerly called diffuse parenchymal lung diseases, are a heterogeneous group of more than 200 rare, non-neoplastic, often chronic disorders. They are primarily characterised by diffuse infiltrates into the lung interstitium. Damage to the lung parenchyma, by various patterns of inflammation and fibrosis, are frequently associated with the involvement of adjacent alveolar epithelium, small distal airways and lung vascular bed, and may result in architectural alterations of the alveolar capillary membrane. Although ILDs regroup distinct pathologies, they share similarities in pathogenesis [1-3]. Thus, patients generally harbour common respiratory symptoms, lung function abnormalities and 
modified exercise adaptation. The most usual and disabling complaint is exertional dyspnoea, frequently responsible for premature exercise interruption and important decline in quality of life [4].

Pathological features are worsened during exercise in ILDs. Respiratory, cardiovascular and/or peripheral responses to exercise can all be modified, making cardiopulmonary exercise testing (CPET) an essential tool to untangle the relative contribution of each one [5-9]. Amongst numerous useful variables, the assessment of ventilatory efficiency is of prime importance in CPET interpretation. Ventilatory efficiency is mainly characterised by the relationship between the output of metabolically produced carbon dioxide $\left(\dot{V}_{\mathrm{CO}_{2}}\right)$ and the quantity of ventilation $\left(\dot{V}_{\mathrm{E}}\right)$ needed to eliminate it. The $\dot{V}_{\mathrm{E}} / \dot{V}_{\mathrm{CO}_{2}}$ index is called ventilatory equivalent for $\mathrm{CO}_{2}$. It mathematically and physiologically depends on $\mathrm{CO}_{2}$ arterial partial pressure $\left(P_{\mathrm{aCO}}\right)$ and the dead space to tidal volume ratio $\left(V_{\mathrm{D}} / V_{\mathrm{T}}\right)$. It can be measured at rest, at its lowest value $\left(\dot{V}_{\mathrm{E}} / \dot{V}_{\mathrm{CO}_{2}}\right.$ nadir), at the first ventilatory threshold $\left(\dot{V}_{\mathrm{E}} / \dot{V}_{\mathrm{CO}_{2}}\right.$ at VTh, VTh being alternatively called anaerobic threshold) and at peak exercise (peak $\dot{V}_{\mathrm{E}} / \dot{V}_{\mathrm{CO}_{2}}$ ). The slope of the relationship can be calculated by linear regression $\left(\dot{V}_{\mathrm{E}}-\dot{V}_{\mathrm{CO}_{2}}\right.$ slope). Depending on the authors, the slope is computed from exercise initiation to either the second ventilatory threshold (alternatively called ventilatory compensation point, after which the $\dot{V}_{\mathrm{E}} / \dot{V}_{\mathrm{CO}_{2}}$ curve steepens) or to peak exercise (on condition that exercise is maximal) [5, 7, 10, 11]. Numerous studies have proven a link between abnormally increased $\dot{V}_{\mathrm{E}} / \dot{V}_{\mathrm{CO}_{2}}$ (i.e. ventilatory inefficiency) and dyspnoea, limited exercise performance and/or poorer outcome in various respiratory or cardiocirculatory conditions, such as chronic obstructive pulmonary disease (COPD), cystic fibrosis, pulmonary hypertension and chronic heart failure [12]. Indeed, multiple mechanisms can interact and result in ventilatory inefficiency: increased physiological dead space, pulmonary vasculopathy, ventilation/ perfusion $\left(\dot{V}_{\mathrm{A}} / \dot{Q}\right)$ mismatch, exercise-induced hypoxaemia, increased metabolic demand, inappropriate hyperventilation, deconditioning, elevated ventilatory neural drive, sympathetic overstimulation, elevated chemoreceptor or ergoreceptor sensitivity, and metabolic acidosis [5-7, 13-15].

The current review belongs to the European Respiratory Review series on "The ventilatory efficiency and its clinical and prognostic value in cardiorespiratory disorders" and provides an up-to-date summary of recent advances concerning the clinical utility of CPET in ILD patients, with particular focus on the physiological and clinical value of ventilatory efficiency.

\section{Epidemiology and classification of ILDs}

The incidence and prevalence of ILDs depend on the case counting method and the geographical area. Taking ILDs as a whole, incidence is considered to be around 20-30 cases per 100000 per year and prevalence around 60-80 cases per 100000 [16, 17]. A French exhaustive study, performed in a multi-ethnic county of Greater Paris, even found a total crude prevalence of 97.9 per 100000 [18]. Sarcoidosis, idiopathic pulmonary fibrosis (IPF) and ILDs related to connective tissue diseases (CTDs)/ vasculitis represent more than one half of all ILD cases, with respective frequencies depending on age, sex and geographical origin.

Considerable progress was made in the past decades to better understand ILDs. Harmonised nomenclature and diagnostic criteria were provided by the 2002 international consensus classification [19], later updated in 2013 [20]. ILDs can be separated into four groups: 1) ILDs of known aetiology, e.g. CTDs/vasculitis, hypersensitivity pneumonitis (HP), iatrogenic ILDs, pneumoconioses; 2) idiopathic interstitial pneumonias (IIPs), e.g. IPF, idiopathic non-specific interstitial pneumonia (iNSIP); 3) sarcoidosis and sarcoid-like granulomatous diseases; 4) other forms of ILDs, e.g. pulmonary Langerhans cell histiocytosis (PLCH), lymphangioleiomyomatosis (LAM), chronic eosinophilic pneumonia and pulmonary alveolar proteinosis (figure 1). Multidisciplinary discussion is mandatory in diagnostic decision-making, and high-resolution computed tomography (HRCT) is often the cornerstone examination in the process [21, 22]. For example, although surgical lung biopsy is the gold standard to establish a diagnosis of IPF, it is not required in a patient with high clinical likelihood (>60 years old, exclusion of other known cause of ILD) and suggestive HRCT pattern [22, 23].

A complementary categorisation was also proposed, according to patterns of disease behaviour (reversible versus irreversible, stable versus progressive), which can be useful in most types of ILDs, regardless of the precise diagnosis, to adjust therapeutic goal and monitoring strategy, and set pertinent endpoints in clinical trials [20, 24, 25]. For example, IPF is the very prototype of the "progressive fibrosing ILD” pattern, characterised by irreversible and self-sustaining fibrosis, progressive worsening in dyspnoea and lung function, associated with early mortality. But it can also be encountered in other ILDs such as iNSIP, CTD-related ILD, HP, stage IV sarcoidosis, drug-induced ILD, pneumoconiosis, acute respiratory distress syndrome-related ILD and unclassifiable IIP. All of them could benefit from the same treatments [26, 27]. Level of dyspnoea, lung function at baseline or in the later course of the disease, exercise performances 


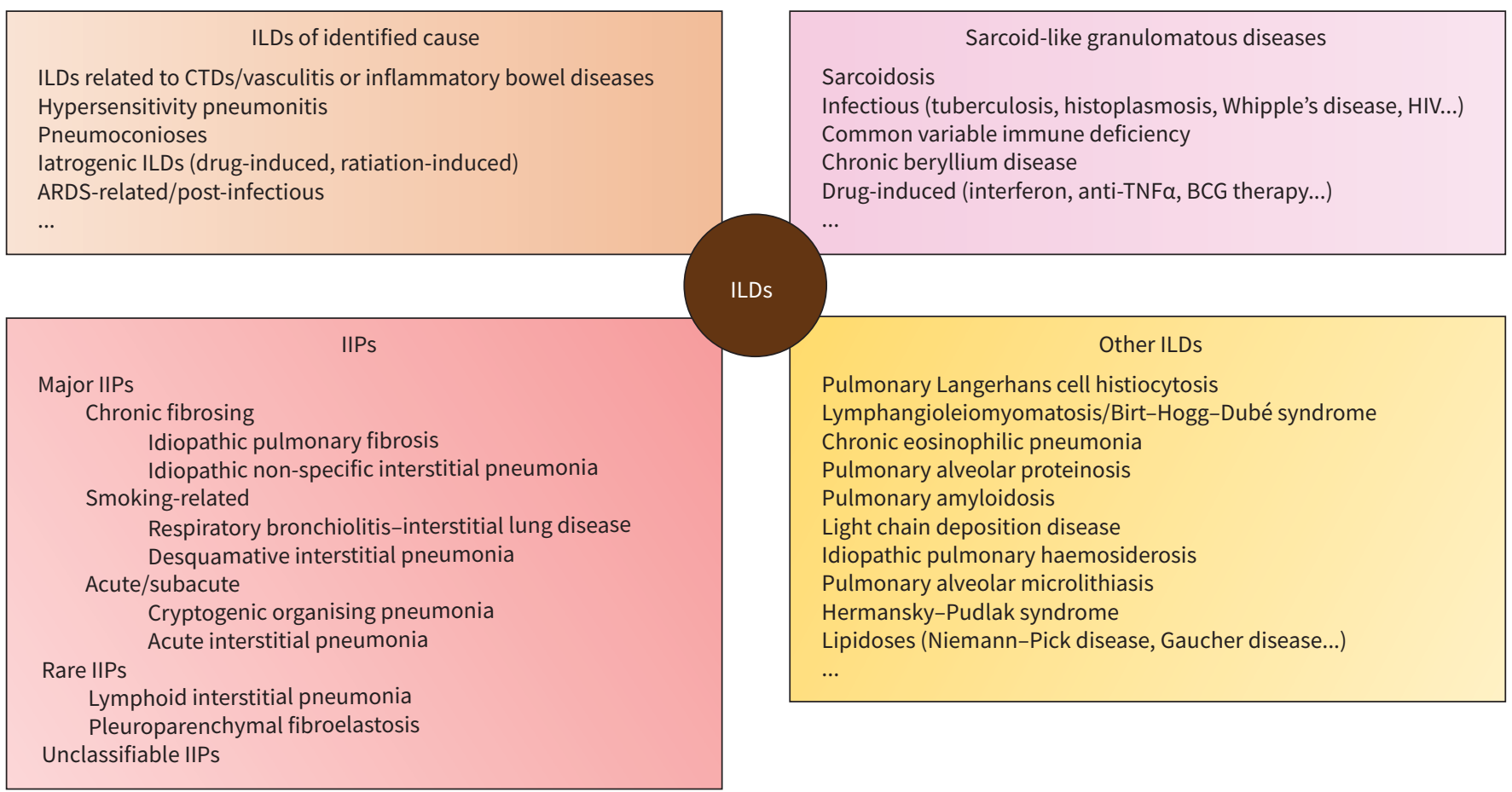

FIGURE 1 Classification of the main interstitial lung diseases (ILDs). By definition, pulmonary oedema from chronic heart failure, neoplastic diseases (lymphangitis carcinomatosa, lymphoma, lepidic growth adenocarcinoma) and chronic infections (pneumocystosis, miliary tuberculosis) are excluded from ILDs of identified cause. Idiopathic interstitial pneumonias (IIPs) are most often sporadic, but familial cases constitute up to 2$20 \%$ of cases. These cases remain classified as IIPs despite the genetic predisposition. In addition to that classification, several rare histologic patterns of ILDs have been described, including acute fibrosing and organising pneumonia (AFOP) and bronchiolocentric patterns of interstitial pneumonia. These rare patterns are not considered as distinct entities of IIPs. The term "non-specific interstitial pneumonia" can apply to a distinct disease classified amongst IIPS (idiopathic non-specific interstitial pneumonia), or a pulmonary histologic pattern that can also be encountered in diverse ILDs of known cause, or even in other IIPS. ARDS: acute respiratory distress syndrome; BCG: bacillus Calmette-Guérin; CTDs: connective tissue diseases; HIV: human immunodeficiency virus; TNF $\alpha$ : tumour necrosis factor alpha.

and exercise-induced desaturation are all major prognostic factors in ILDs, alongside the extent of fibrosis on HRCT (particularly with a honeycombing pattern) and the presence of precapillary PH [22, 28-31].

\section{Resting pulmonary function tests (PFTs) in ILDs}

PFTs are essential to the diagnosis and to assess disease severity, prognosis and response to therapy. They typically show a low diffusion capacity of the lungs for carbon monoxide $\left(D_{\text {LCO }}\right)$, associated with a restrictive ventilatory defect (RVD) with reduction of total lung capacity (TLC) and vital capacity (VC). Forced expiratory volume in one second $\left(\mathrm{FEV}_{1}\right) / \mathrm{VC}$ ratio is often normal or even increased [19, 32-35]. Pathophysiological mechanisms for $D_{\mathrm{LCO}}$ changes in ILDs are almost always intertwined: $\dot{V}_{\mathrm{A}} / \dot{Q}$ mismatch being the main factor, in combination with alveolar capillary membrane thickening, reduction in gas exchange surface due to RVD and/or rarefaction of the pulmonary capillary bed. Therefore, $D_{\text {LCO }}$ alteration is generally the first anomaly to be observed, decreasing to a greater extent than other functional variables when expressed as a percentage of reference values. Gas exchange impairment leads to widened alveolar-arterial oxygen pressure difference $\left(P_{(\mathrm{A}-\mathrm{a}) \mathrm{O}_{2}}\right)$ and hypoxaemia, first at exercise and ultimately at rest when $D_{\text {LCO }}$ has severely declined [32-39]. Abnormal respiration mechanics, with increased lung recoil pressure and decreased lung compliance, are responsible for lung volume reduction. Depending on the criteria used, airway obstruction has been described in $8.8 \%$ to $57 \%$ of sarcoidosis patients [40-42] Obstructive ventilatory defect (OVD), as defined by an excessively decreased $\mathrm{FEV}_{1} / \mathrm{VC}$ ratio, can also occur in other ILDs with particular airway involvement: rheumatoid arthritis, Sjögren's syndrome or inflammatory bowel disease associated ILD, HP, PLCH, LAM, silicosis, chronic eosinophilic pneumonia, respiratory bronchiolitis-ILD and chronic beryllium disease. OVD can occur independently or associated with RVD, such patients with mixed ventilatory defect tend to exhibit relatively preserved TLC and residual volume. In patients with combined pulmonary fibrosis and emphysema, the $\mathrm{FEV}_{1} / \mathrm{VC}$ ratio is only 
reduced in cases of major emphysema extent. Despite relatively preserved lung volumes, these patients characteristically present with a severe, out-of-proportion, decrease in $D_{\text {LCO }}[35,43]$.

\section{Exercise pathophysiology and CPET in ILDs}

Resting PFTs cannot always predict exercise performance in individual ILD patients [37, 44, 45]. The six-minute walk test and CPET are valuable to assess functional status and detect precocious alteration in gas exchange. CPET is often mandatory for setting the exercise training intensity for pulmonary rehabilitation. CPET also helps to decipher the mechanisms of dyspnoea and exercise limitation of unclear origin, especially when PFTs and transthoracic echocardiogram (TTE) are either normal or both impaired. This is all the more important in ILDs with potential extrapulmonary involvement (sarcoidosis, CTDs) or when deconditioning with peripheral muscle weakness is suspected, which is a frequent situation in chronic lung diseases [5, 46-50]. Moreover, cardiovascular comorbidities are known to be frequent in IPF patients [51-53]. Given the huge variety of reasons for functional impairment, and the numerous modalities of decline, with many potential clinical and therapeutic questions, CPET positioning and timing during the course of ILDs is not unique [5, 47, 50]. Even if the minimal clinically important difference is unclear for CPET variables, repeated assessment is feasible and could be of great help in personalised medical decisions [54], especially as it can identify the mechanisms of improvement or deterioration. Data are scarce on this topic, but serial CPETs were used to assess the benefits of some pharmacological or non-pharmacological interventions, such as pulmonary rehabilitation [55-58].

Compared to age- and sex-matched healthy subjects, ILD patients regularly harbour a decrease in maximal $\mathrm{O}_{2}$ uptake (peak $\dot{V}_{\mathrm{O}_{2}}$ ) and maximal work rate (WR) (table 1) [5, 6, 46-50]. Indeed, various mechanisms can jointly contribute to that limitation, as ILDs induce numerous changes in physiologic and sensory responses to exercise (figure 2) [59-62]. Patients with ILD often hyperventilate at rest and during exercise, as demonstrated by a low $P_{\mathrm{aCO}}[39,63]$. Reduced lung compliance, with increased elastic loading on respiratory muscles and lung elastic recoil, alongside with stimulation of thoracic mechanoreceptors, limits the rise in $V_{\mathrm{T}}$ below $50-60 \%$ of maximal $\mathrm{VC}$, leading to a characteristic shallow breathing pattern with high respiratory frequency $\left(f_{\mathrm{R}}\right)$. A low or absent breathing reserve (BR) at peak exercise frequently ensues [59, 60, 64-67]. Although the reduction in $V_{\mathrm{T}}$ is an effective strategy to minimise the inspiratory elastic work of breathing during exercise, the compensatory tachypnoea increases $V_{\mathrm{D}}$. Also, impaired alveolar capillary diffusing capacity, low $\dot{V}_{\mathrm{A}} / \dot{Q}$ regions and reduced mixed $\mathrm{O}_{2}$ venous partial pressure $\left(P_{\overline{\mathrm{v}}}\right)$ lead to exercise-induced hypoxaemia, $P_{\mathrm{aO}_{2}}$ being inversely proportional to WR [37, 39, 59, 61, 68, 69]. Both dynamic restrictive mechanical constraints and hypoxaemia-induced stimulation of peripheral chemoreceptors favour alveolar hyperventilation. In addition to $\dot{V}_{\mathrm{A}} / \dot{Q}$ mismatch, it results in ventilatory inefficiency: high $V_{\mathrm{D}} / V_{\mathrm{T}}$ ratio (remaining abnormally stable or even increasing in exercising ILD patients) and increased $\dot{V}_{\mathrm{E}} / \dot{V}_{\mathrm{CO}_{2}}$ relationship (at any given level of $\mathrm{O}_{2}$ consumption). Increased pulmonary vascular resistance during exercise, from hypoxic pulmonary vasoconstriction and capillary bed remodelling or destruction, also participates in the alteration of ventilatory efficiency by increasing effective $V_{\mathrm{D}}[39,59$, 61, 67, 68, 70, 71]. Dynamic hyperinflation (DH), i.e. a decrease in inspiratory capacity during exercise, was documented in ILDs involving airways, such as LAM, PLCH and HP [72-75]. Since DH has been demonstrated in patients with pulmonary arterial hypertension (PAH) and chronic thromboembolic pulmonary hypertension [76, 77], it could theoretically be present in patients with ILD and associated PH, but this issue has not yet been investigated. Several of the aforementioned pathophysiological mechanisms may be intertwined in a single individual, and all of them can be responsible for an elevated ventilatory neural drive, at any given WR, largely explaining the level of exertional breathlessness in ILD patients [67, 78-81]. An example of CPET can be found in figure 3. Importantly, cycling frequently underestimates the severity of exercise-related hypoxaemia in ILD patients.

Skeletal muscle dysfunction (SMD) is another important feature contributing to dyspnoea and exercise limitation in patients with various ILDs [82-86]. Not only quadriceps muscle strength, endurance and/or resistance to fatigue are reduced in ILDs compared to healthy individuals, but SMD seems to be more important in IPF than in COPD [87]. Indeed, leg discomfort is commonly recounted by ILD patients while exercising [57, 88, 89]. On the other hand, clinical significance of potential respiratory muscle impairment is debated. Diaphragmatic dysfunction can be encountered in advanced stages, but peripheral muscle weakness often seems to prevail [90]. Increased work of breathing and ventilatory inefficiency are thought to equate to chronic loading of respiratory muscles, which could preserve their function. All in all, the precise mechanisms of SMD in ILDs are still poorly understood. Several factors are suspected to participate: physical inactivity, ageing, malnutrition, arterial hypoxaemia resulting in tissue hypoxia, systemic inflammatory and oxidative stress, steroid myopathy, and/or direct insult by systemic disease [91, 92]. 
ILD

Peak $\dot{V}_{\mathrm{O}_{2}}$

Peak WR

$\Delta \dot{V}_{\mathrm{O}_{2}} / \Delta W R$

Maximal $\dot{V}_{\mathrm{O}_{2}} / \mathrm{HR}$

(oxygen pulse)

Peak HR

$\Delta \mathrm{HR} / \Delta \dot{V}_{\mathrm{O}_{2}}$

BR

Peak $f_{\mathrm{R}}$

Maximal $V_{T}$

$\dot{V}_{\mathrm{E}} / \dot{V}_{\mathrm{CO}_{2}}$ at VTh

$\dot{V}_{\mathrm{E}} / \dot{V}_{\mathrm{O}_{2}}$ at VTh

$P_{\mathrm{ETCO}}$

$S$

$\mathrm{PaO}_{2}$

Peak $P_{(\mathrm{A}-\mathrm{a}) \mathrm{O}_{2}}$

Peak $V_{\mathrm{D}} / V_{\mathrm{T}}$

Other features

\begin{tabular}{ll}
\hline Reduced & Reduced \\
Reduced & Reduced \\
\hline Normal or low & Normal or low \\
\hline Normal or low & Likely normal \\
Likely normal & Likely normal \\
& \\
Likely reduced & Likely reduced \\
Variable & Variable \\
Reduced & Reduced \\
\hline Accelerated ++ & Normal or accelerated \\
Reduced & Likely reduced \\
Elevated ++ & Variable \\
\hline Elevated ++ & Variable \\
\hline Low & Variable, likely rising \\
Reduced ++ & Reduced \\
\hline Reduced ++ & Reduced \\
Widened ++ & Widened \\
High ++ sometimes not decreasing & High sometimes not decreasing \\
More severe hypoxaemia on & Frequent dynamic \\
walking than cycling & hyperinflation \\
\hline
\end{tabular}

$\mathrm{CHF}$

Reduced

Reduced

Low (early VTh)

Reduced ++

Reduced ++

Normal or low

Elevated

Normal

Normal or accelerated

Likely normal

Elevated

Elevated

Normal or low plateau

Normal

Likely normal

Likely norma

Normal or high

Possible oscillatory breathing
$\mathrm{PH}$

Reduced

Reduced

Low (early VTh)

Reduced

Reduced

Likely normal

Elevated

Normal

Normal or accelerated

Normal or reduced

Elevated ++

Elevated ++

Low and decreasing

Reduced ++

Reduced ++

Widened ++

High ++ likely increasing

Positive $P_{(\mathrm{a}-\mathrm{ET}) \mathrm{CO}_{2}}$ during exercise
Deconditioning

Reduced

Reduced

Low (early VTh)

Reduced

Reduced

Normal

Elevated

Normal

Normal or accelerated

Likely normal

Normal or elevated

Normal or elevated

Normal

Normal

Normal

Normal

Likely normal

When severe, difficult to differentiate from cardiocirculatory limitation

Depending on the severity of underlying disease, pathologic features may not all be present in a given ILD patient. Conversely, associated comorbidities, obesity and/or negative inotropic drugs may result in mixed limitation pattern. ++ signs indicate potential higher variation from normal values. BR: breathing reserve; CHF: chronic heart failure; COPD: chronic obstructive pulmonary disease; $f_{\mathrm{R}}$ : respiratory frequency; HR: heart rate; $P_{(\mathrm{A}-\mathrm{a}) \mathrm{O}_{2}}$ : alveolar-arterial oxygen pressure difference; $P_{(\mathrm{a}-\mathrm{ET}) \mathrm{CO}_{2}}$ : arterial-end tidal carbon dioxide pressure difference; $P_{\mathrm{aO}}$ : arterial oxygen partial pressure; $P_{\mathrm{ETCO}}$ : end-tidal carbon dioxide partial pressure; PH: pulmonary hypertension; $S_{\mathrm{aO}_{2}}$ : oxygen saturation; $\dot{V}_{\mathrm{CO}_{2}}$ : carbon dioxide output; $V_{\mathrm{D}}$ : dead space; $\dot{V}_{\mathrm{E}}$ : total ventilation; $V_{\mathrm{O}_{2}}$ : oxygen uptake; $V_{T}$ : tidal volume; $V T h$ : first ventilatory threshold (anaerobic threshold); WR: work rate. 


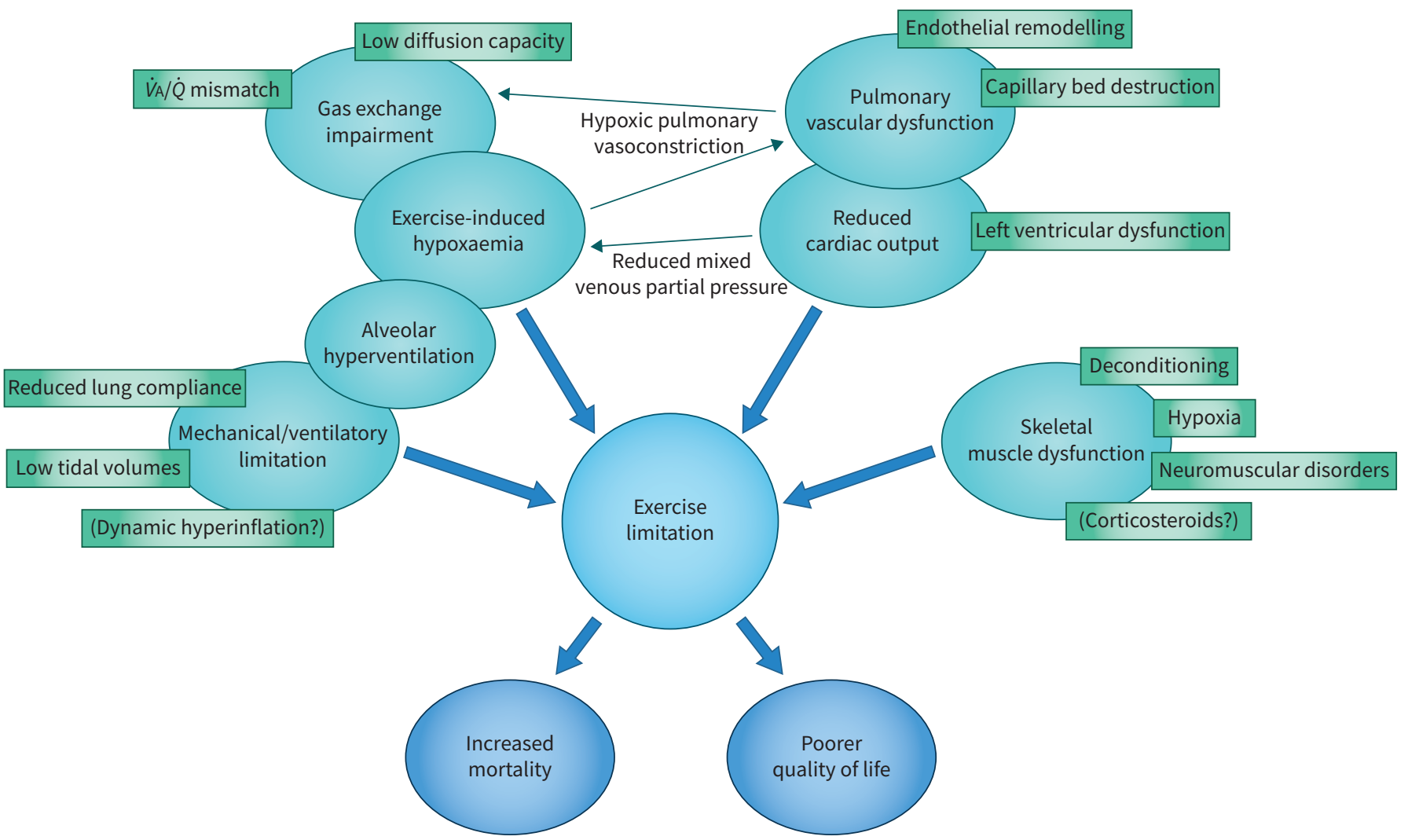

FIGURE 2 Mechanisms of exercise limitation in interstitial lung diseases. The combination of increased dead space and alveolar hyperventilation results in an abnormally elevated $\dot{V}_{\mathrm{E}} / \dot{V}_{\mathrm{CO}_{2}}$ ratio. Ventilatory inefficiency and impairment of pulmonary gas exchange are key mechanisms of dyspnoea and exercise intolerance in patients with interstitial lung diseases (ILDs). Some ILDs may present with specific neuromuscular disorders (e.g. in sarcoidosis or connective tissue diseases) or heart involvement (e.g. in sarcoidosis or systemic sclerosis). Additionally, associated cardiovascular comorbidities are common (e.g. in idiopathic pulmonary fibrosis). $\dot{V}_{\mathrm{A}} / \dot{Q}:$ ventilation/perfusion.

\section{Diagnostic utility of ventilatory efficiency in ILDs}

\section{Assessment of functional impairment (the example of sarcoidosis)}

CPET may be useful to detect precocious functional impact in the context of ILD. Exercise limitation, as defined by peak $\dot{V}_{\mathrm{O}_{2}}<84 \%$ of predicted value, affects $50-88 \%$ of sarcoidosis patients taken as a whole [93, 94]. But even those with still normal resting PFTs can harbour reduced peak $\dot{V}_{\mathrm{O}_{2}}$ [44, 45] or ventilatory inefficiency with abnormally increased $\dot{V}_{\mathrm{E}} / \dot{V}_{\mathrm{CO}_{2}}$ [95]. In a US prospective study that included 39 patients with biopsy-proven sarcoidosis, Aтноs et al. [96] reported that disease staging by chest radiography was the best overall predictor of exercise performance. However, several other studies failed to find a correlation between disease staging and peak $\dot{V}_{\mathrm{O}_{2}}[95,97,98]$. Along the same lines, although ventilatory inefficiency seems to be a sensitive marker of early functional impairment in sarcoidosis, no correlation was found in these studies between disease staging and $\dot{V}_{\mathrm{E}} / \dot{V}_{\mathrm{CO}_{2}}$, measured at VTh or at peak exercise [9598]. One possible explanation is that organs other than lungs can be involved in sarcoidosis and alter the ventilatory response to exercise. Still, MAGRì et al. [99] found that the $\dot{V}_{\mathrm{E}}-\dot{V}_{\mathrm{CO}_{2}}$ slope was negatively correlated with resting $D_{\text {LCO }}(r=-0.85 ; \mathrm{p}<0.001)$ and positively correlated with the change in arterial $\mathrm{O}_{2}$ saturation $\left(\Delta S_{\mathrm{aO}_{2}}\right)$ between rest and peak exercise $(r=0.68 ; \mathrm{p}<0.001)$ in 30 patients with stage 2-4 sarcoidosis. In the work by MiLler et al. [95], 78\% of sarcoidosis patients with altered $D_{\text {LCO }}$ had an abnormally elevated $\dot{V}_{\mathrm{E}} / \dot{V}_{\mathrm{CO}_{2}}>34$ at VTh (mean: $45 \pm 9$ ) versus only $38 \%$ of those with normal $D_{\mathrm{LCO}}$. Finally, in a more recent monocentric prospective work with 83 sarcoidosis patients, KaLLianos et al. [100] found that $\dot{V}_{\mathrm{E}} / \dot{V}_{\mathrm{CO}_{2}}$ at VTh progressively increased from stage 1 to stage 4 groups. Interestingly, a principal component analysis showed that elevated $\dot{V}_{\mathrm{E}} / \dot{V}_{\mathrm{CO}_{2}}$, peak $\dot{V}_{\mathrm{E}} / \dot{V}_{\mathrm{O}_{2}}$ and $V_{\mathrm{D}} / V_{\mathrm{T}}$, all markers of inappropriate ventilatory response to exercise, were correlated with radiographic stage and with the presence of extrapulmonary locations. One limit of this study, however, was that it included only nine patients with stage 4 sarcoidosis. 
a)

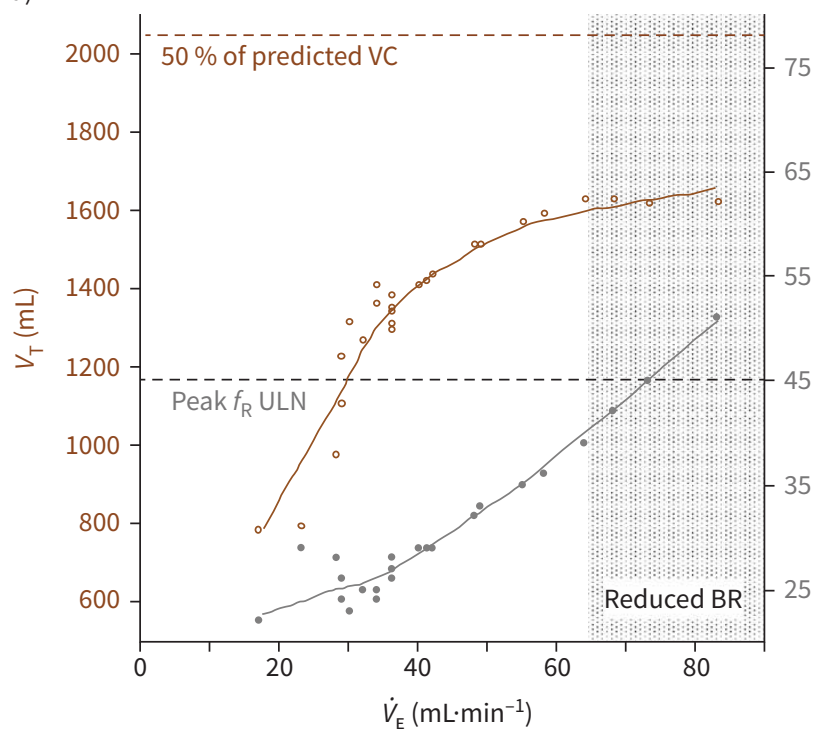

c)

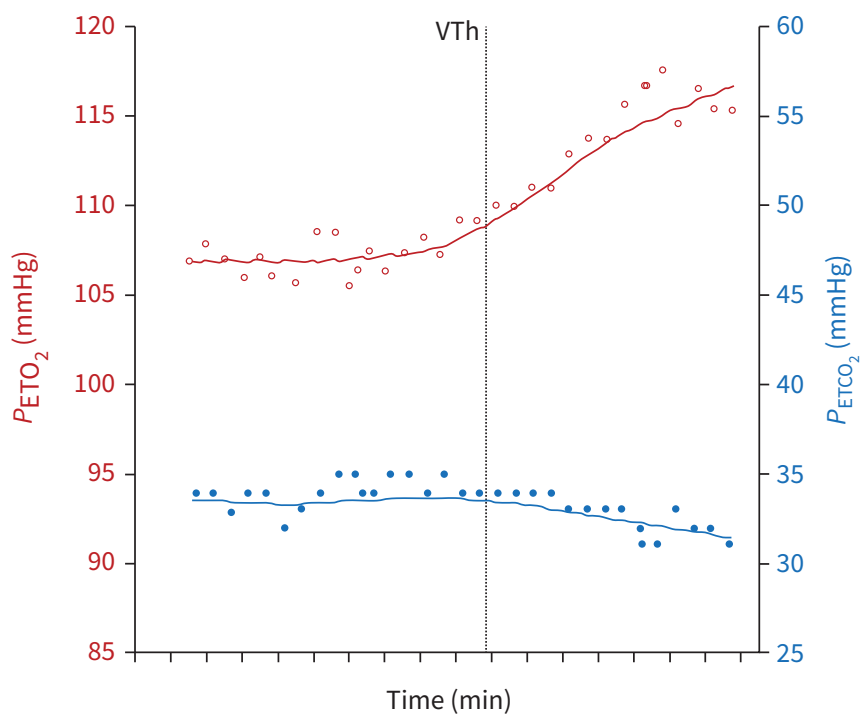

b)

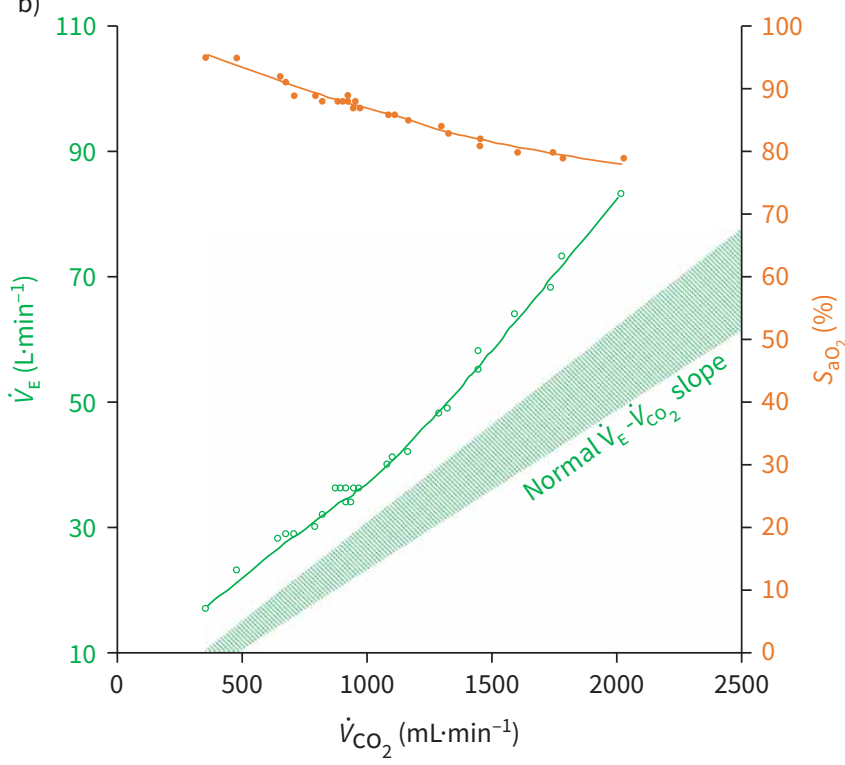

d)

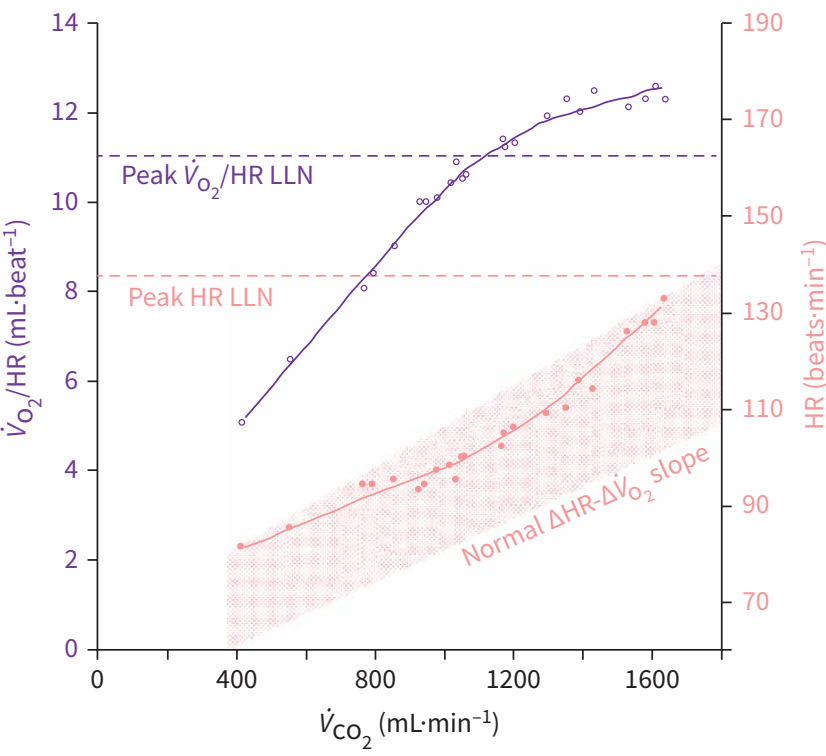

FIGURE 3 Cardiopulmonary exercise test of a 70-year-old male patient with idiopathic pulmonary fibrosis. Resting pulmonary function tests showed restrictive ventilatory defect (vital capacity $=56 \%$ of predicted value) and low diffusion capacity for carbon monoxide $\left(D_{\mathrm{LCO}}=40 \%\right)$. Peak $\dot{V}_{\mathrm{O}_{2}}$ was mildly reduced $\left(15.6 \mathrm{ml} \cdot \mathrm{kg}^{-1} \cdot \mathrm{min}^{-1}, 78 \%\right.$ of predicted value), submaximal heart rate (HR) and null breathing reserve (BR) at peak exercise indicated respiratory limitation. Ventilatory response is shown in panels a) and b); tidal volume $\left(V_{T}\right)$ could rise up to $71 \%$ of maximal vital capacity (VC), but still with an accelerated respiratory frequency $\left(f_{\mathrm{R}}\right)$ up to 51 breaths $\cdot \mathrm{min}^{-1}$. Ventilatory inefficiency was documented by a $\dot{V}_{\mathrm{E}}-\dot{V}_{\mathrm{CO}_{2}}$ slope value of 40 and a $\dot{V}_{\mathrm{E}} / \dot{V}_{\mathrm{CO}_{2}}$ nadir of 37. Oxygen saturation $\left(\mathrm{S}_{\mathrm{aO}_{2}}\right)$ progressively decreased with exercise intensity and peak alveolar-arterial oxygen pressure difference $\left(P_{(\mathrm{A}-\mathrm{a}) \mathrm{O}_{2}}\right)$ was $55 \mathrm{mmHg}$. Hyperventilation resulted in low end-tidal carbon dioxide partial pressure $\left(P_{\mathrm{ETCO}}\right)$ and high end-tidal oxygen partial pressure $\left(P_{\mathrm{ETO}_{2}}\right)$ (panel $\mathrm{c}$ ), with increased dead space (resting and peak $V_{\mathrm{D}} / V_{\mathrm{T}}$ of 0.44 and 0.37 , respectively). Theoretical maximal $\mathrm{HR}$ was not achieved due to respiratory limitation, though cardiocirculatory response was satisfactory and maximal oxygen pulse was $88 \%$ of predicted value (panel d). BR: breathing reserve; $D_{\mathrm{LCO}}$ : diffusion capacity of the lung for carbon monoxide; $f_{\mathrm{R}}$ : respiratory frequency; HR: heart rate; LLN: lower limit of normal; $P_{(\mathrm{A}-\mathrm{a}) \mathrm{O}_{2}}$ : alveolar-arterial oxygen pressure difference; $P_{\mathrm{ETCO}}$ : end-tidal carbon dioxide partial pressure; $P_{\mathrm{ETO}}$ : end-tidal oxygen partial pressure; PFTs: pulmonary function tests; $\mathrm{S}_{\mathrm{aO}_{2}}$ : oxygen saturation; ULN: upper limit of normal; VC: vital capacity; $\dot{V}_{\mathrm{CO}_{2}}$ : carbon dioxide output; $V_{\mathrm{D}}$ : dead space; $\dot{V}_{\mathrm{E}}$ : total ventilation; $\dot{V}_{\mathrm{O}_{2}}$ : oxygen uptake; $V_{\mathrm{T}}$ : tidal volume; $V \mathrm{VTh}$ f first ventilatory threshold.

\section{Discrimination between IIPs}

As shown in table 1 and figure 4 , an increased $\dot{V}_{\mathrm{E}} / \dot{V}_{\mathrm{CO}_{2}}$ ratio is a hallmark of many cardiopulmonary conditions. Thus, it is not sufficient alone to discriminate between ILD and a differential diagnosis, but the 
global pattern of exercise response must be taken into account [5, 9]. Yet, in a Canadian cross-sectional study comparing 16 patients with mild-to-moderate ILD (mean VC: $73 \pm 12 \%$ of predicted value; mean TLC: $64 \pm 10 \%$; mean $D_{\text {LCO }}: 44 \pm 12 \%$ ) to 16 sex- and age-matched patients with mild-to-moderate COPD (mean $\mathrm{FEV}_{1}$ : $63 \pm 22 \%$; mean $D_{\mathrm{LCO}}: 62 \pm 22 \%$ ) and 16 healthy subjects, FAISAL et al. [67] found that ventilatory inefficiency was significantly greater in ILD patients than in COPD patients, and even greater than in controls: $33 \pm 5$ versus $31 \pm 4$ and $27 \pm 3$ for $\dot{V}_{\mathrm{E}} / \dot{V}_{\mathrm{CO}_{2}}$ nadir, respectively $(\mathrm{p}<0.05)$. These results were identical regardless of the calculation method $\left(\dot{V}_{\mathrm{E}} / \dot{V}_{\mathrm{CO}_{2}}\right.$ at rest, $\dot{V}_{\mathrm{E}}-\dot{V}_{\mathrm{CO}_{2}}$ slope, peak $\left.\dot{V}_{\mathrm{E}} / \dot{V}_{\mathrm{CO}_{2}}\right)$. Nevertheless, KISAKA et al. [101] found no difference between eight ILD patients and nine COPD patients when measuring $\dot{V}_{\mathrm{E}} / \dot{V}_{\mathrm{CO}_{2}}$ at VTh: $36 \pm 5$ versus $37 \pm 8$, as compared to $27 \pm 3$ in nine healthy controls. Six patients with pulmonary vasculopathy were also enrolled and they harboured the greatest $\dot{V}_{\mathrm{E}} / \dot{V}_{\mathrm{CO}_{2}}$ at VTh $(43 \pm 5)$.

Given the particular sensitivity of CPET, HAGMEYER et al. [102] hypothesised that it could perhaps help to distinguish between two IIPs in the early course of the disease. In a prospective monocentric study, they compared exercise variables of 27 mild-to-moderate untreated IIPs, divided into two groups: 14 patients with IPF and 13 with iNSIP. They reported a significantly lower mean peak $\dot{\mathrm{VO}}_{2}$ in IPF patients $(74 \pm 31 \%$ versus $99 \pm 15 \%$; $\mathrm{p}=0.01$ ) and a significantly higher mean $\dot{\mathrm{V}} / \dot{\mathrm{V}}_{\mathrm{CO}_{2}}$ at any given level of $\mathrm{O}_{2}$ consumption (e.g. $50 \pm 14$ versus $38 \pm 6$ at VTh; $\mathrm{p}=0.01$ ). Nonetheless, one should remain cautious before integrating these findings into a diagnostic tree of IIPs. In fact, mean forced VC (FVC) was lower in IPFs $(65 \pm 12 \%$ versus $80 \pm 23 \%$ ), suggesting a more important alteration of lung compliance in this group, but no indication was given about $f_{\mathrm{R}}$, although $\dot{V}_{\mathrm{E}} / \dot{V}_{\mathrm{CO}_{2}}$ at VTh is presumably correlated with $f_{\mathrm{R}}$ at peak exercise in IIPs [103]. IPF patients also tended to exhibit a wider mean peak $P_{(\mathrm{A}-\mathrm{a}) \mathrm{O}_{2}}(65 \pm 11 \mathrm{mmHg}$ versus $55 \pm 14$ $\mathrm{mmHg}$ ), which could have participated in an accelerated $f_{\mathrm{R}}$. Lastly, mean $D_{\mathrm{LCO}}$ tended to be lower in IPFs (52 $\pm 22 \%$ versus $62 \pm 16 \%$ ), especially since $\dot{V}_{\mathrm{E}} / \dot{V}_{\mathrm{CO}_{2}}$ values differed amongst $D_{\mathrm{LCO}}$ quartiles; this difference could have accounted in part for a pulmonary vascular involvement that was not evaluated.

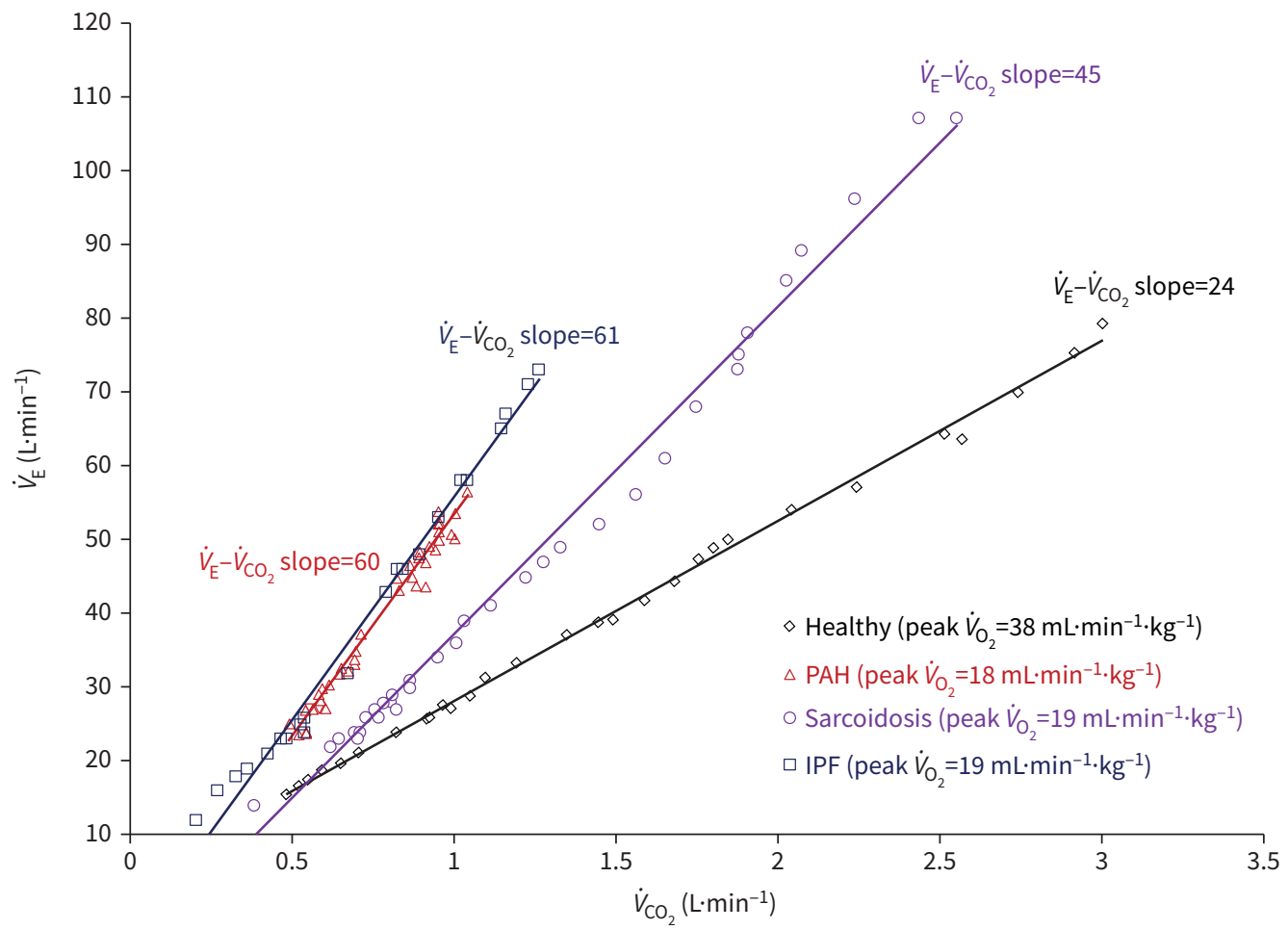

FIGURE 4 Examples of ventilatory efficiency slope ( $\dot{\mathrm{V} E}-\dot{\mathrm{V}} \mathrm{CO}_{2}$ slope) in a healthy subject presenting with a peak oxygen uptake $\left(\mathrm{VO}_{2}\right)$ of $38 \mathrm{ml} \cdot \mathrm{min}^{-1} \cdot \mathrm{kg}^{-1}$ (black line and rhomboid), a patient with pulmonary sarcoidosis presenting with a peak $\mathrm{VO}_{2}$ of $19 \mathrm{ml} \cdot \mathrm{min}^{-1} \cdot \mathrm{kg}^{-1}$ (violet line and circles), a patient with pulmonary arterial hypertension (PAH) presenting with a peak $\mathrm{VO}_{2}$ of $18 \mathrm{ml} \cdot \mathrm{min}^{-1} \cdot \mathrm{kg}^{-1}$ (red line and triangles) and a patient with idiopathic pulmonary fibrosis (IPF) presenting with a peak $\dot{\mathrm{V}}_{2}$ of $19 \mathrm{ml} \cdot \mathrm{kg}^{-1} \cdot \mathrm{min}^{-1}$ (blue line and squares). 


\section{Early detection of pneumoconiosis in patients at risk}

The assessment of ventilatory efficiency could play a role in monitoring patients exposed to inhaled mineral dust. Duvenkamp et al. [104] compared 20 former coal miners with anthracosilicosis to 24 healthy volunteers and showed that mean $\dot{V}_{\mathrm{E}} / \dot{V}_{\mathrm{CO}_{2}}$ at a submaximal WR of 50 watts was abnormally elevated in patients ( $39 \pm 5$ versus $31 \pm 4 ; \mathrm{p}<0.0001$ ) and was not correlated with the radiological grading of the disease. In a later French study of 38 patients with mild-to-moderate anthracosilicosis, all complaining of dyspnoea and divided into four groups in accordance with resting PFTs, FAVRE et al. [105] found a ventilatory inefficiency across all groups, including 21 patients with normal resting PFTs (mean peak $\dot{V}_{\mathrm{E}} / \dot{V}_{\mathrm{CO}_{2}}$ in the normal PFT group: $39 \pm 8$ ). Peak $\dot{V}_{\mathrm{E}} / \dot{V}_{\mathrm{CO}_{2}}$ was negatively correlated with $D_{\mathrm{LCO}}$ and positively correlated with $\Delta S_{\mathrm{aO}_{2}}$. One proposed reason why CPET was more sensitive than PFTs was that cardiac limitation (mixed or isolated) was involved in 12 (31\%) of the patients having completed maximal exercise. In some coal miners, ventilatory inefficiency could also reveal the presence of small airway dysfunction [106]. Somewhat analogous observations were made with asbestosis: one German study compared 19 patients with former occupational asbestos exposure and variable resting PFTs to 24 healthy subjects; mean $\dot{V}_{\mathrm{E}}$ / $\dot{V}_{\mathrm{CO}_{2}}$ was higher in patients than in controls, but no correlation was found between ventilatory insufficiency and radiological severity of the disease [107].

\section{Non-invasive diagnosis of coexisting $\mathrm{PH}$}

More importantly, patients with ILD are at high risk of developing $\mathrm{PH}$. Guidelines have proposed risk stratification based on CPET variables, including peak $\dot{V}_{\mathrm{O}_{2}}, \dot{V}_{\mathrm{E}} / \dot{V}_{\mathrm{CO}_{2}}$ and end-tidal $\mathrm{CO}_{2}$ partial pressure $\left(P_{\mathrm{ETCO}_{2}}\right)$, to evaluate patients with suspected PAH, either idiopathic or CTD-related. ILD patients with disproportionate $\dot{V}_{\mathrm{E}} / \dot{V}_{\mathrm{CO}_{2}}$ must be suspected of pulmonary vasculopathy as well: in the context of ILD, PH may worsen pulmonary gas exchange and exacerbate the already exaggerated ventilatory response to exercise [15, 108, 109]. Specifically, in IPF patients, at least four studies, including two with prospective designs, have shown that $\dot{V}_{\mathrm{E}} / \dot{V}_{\mathrm{CO}_{2}}$ was the best functional variable able to predict the coexistence of PH [110-113]. In another retrospective monocentric series of lung transplant candidates with various severe ILDs (almost half of them non-IPF), peak $\dot{V}_{\mathrm{E}} / \dot{V}_{\mathrm{CO}_{2}}, P_{\mathrm{ETCO}}$ and resting $D_{\mathrm{LCO}}$ were significantly associated with PH [114]. Ventilatory inefficiency was also assessed in a Brazilian prospective monocentric study of 32 PLCH patients with subsequent CPET and right heart catheterisation (RHC). The 13 (41\%) patients with coexisting $\mathrm{PH}$ showed worse resting PFTs (FEV $\left.1, D_{\mathrm{LCO}}\right)$ and tended to have a greater $\dot{V}_{\mathrm{E}}-\dot{V}_{\mathrm{CO}_{2}}$ slope (38 \pm 15 versus $30 \pm 5$; $\mathrm{p}=0.07$ ), but this last result was not statistically significant because of the small population size and large inter-subject variability [74]. In a prospective monocentric study with 27 mild-to-moderate ILDs (mean FVC: 68 $\pm 3 \%$; mean $D_{\mathrm{LCO}}: 45 \pm 5 \%$ ), amongst which 14 (52\%) were IPFs, Degani-Costa et al. [115] performed invasive haemodynamic measurements during exercise to explore pulmonary vascular dysfunction (PVD), defined in accordance with the ratio between mean pulmonary artery pressure and cardiac output (mPAP- $\dot{\mathrm{Q}}$ $\mathrm{C}$ slope). Although only seven patients had $\mathrm{PH}$ with elevated $\mathrm{mPAP} \geqslant 25 \mathrm{mmHg}$ at rest, PVD during exercise was identified in 15, harbouring higher $\dot{V}_{\mathrm{E}} / \dot{V}_{\mathrm{CO}_{2}}$ at VTh than patients without PVD (45 \pm 2 versus 38 \pm 1 ; $\mathrm{p}=0.015)$, and higher peak $V_{\mathrm{D}} / V_{\mathrm{T}}(39 \pm 2$ versus $30 \pm 2$; $\mathrm{p}=0.008)$.

In the particular case of systemic sclerosis (SSc), PAH may occur even without associated ILD. In SSc patients without respiratory limitation at exercise (normal BR at peak $\dot{V}_{\mathrm{O}_{2}}$ ), high $\dot{V}_{\mathrm{E}} / \dot{V}_{\mathrm{CO}_{2}}$ (at VTh or at maximal exercise) and decreasing $P_{\mathrm{ETCO}}$ from start of exercise to VTh were said to discriminate pulmonary vasculopathy from left ventricular dysfunction [116, 117]. In the US prospective series from DumitREScu et al. [116], which included 28 SSc patients with echocardiographic systolic pulmonary artery pressure (sPAP) $\leqslant 35 \mathrm{mmHg}$, an early pulmonary vasculopathy profile was identified in eight (62\%) out of the 13 patients with ILD on HRCT (ILD-SSc). Nevertheless, these studies chose to solely characterize the predominant mechanism of exercise limitation for each patient. On the other side, a French retrospective multicentric study by MARTIS et al. [118], with 27 SSc patients having performed CPET, revealed that a combination of putative mechanisms was involved in 19 cases (70\%). CPET found an ILD pattern in 16 patients (60\%), which was 78\% concordant with HRCT observations. Among the 10 patients referred for RHC, CPET variables indicating a pulmonary vasculopathy were more concordant with RHC than with TTE. Indeed, a good correlation between RHC and CPET variables, including $\dot{V}_{\mathrm{E}} / \dot{V}_{\mathrm{CO}_{2}}$, was previously described in SSc [119]. In combination with the DETECT screening algorithm (associating PFTs, biological markers and TTE in SSc patients with $D_{\mathrm{LCO}}<60 \%$ and a disease duration $>3$ years) [120], a $\dot{V}_{\mathrm{E}}-\dot{V}_{\mathrm{CO}_{2}}$ slope $>36$ was suggested to be able to diminish the need for RHC referral, given its excellent sensitivity and negative predictive value. However, this threshold must be confirmed for ILD-SSc patients, since this Italian prospective multicentric cohort with 96 SSc patients included only seven with mild-to-intermediate lung fibrosis on HRCT [121].

The presence of coexisting PH in a patient with ILD and/or SSc is of high prognostic significance, and ventilatory inefficiency has been shown to be associated with worse outcomes in various configurations. 
Prognostic implications of ventilatory inefficiency in ILDs

Many correlations were uncovered in the literature between survival and CPET variables, indicating that exercise limitation has a tremendous effect on ILD patients. In a US monocentric study that retrospectively analysed 117 patients with newly diagnosed IPF, FELL et al. [122] were the first to report that baseline peak $\dot{V}_{\mathrm{O}_{2}}<8.3 \mathrm{ml} \cdot \mathrm{kg}^{-1} \cdot \mathrm{min}^{-1}$ was independently associated with a threefold increase in mortality. This association was later confirmed in a German multicentric cohort (retrospective analysis of prospectively collected data), with 135 IPF patients having performed PFTs, CPET and RHC, in which peak $\dot{V}_{\mathrm{O}_{2}}$ was the only functional variable independently predictive of transplant-free survival. Yet, the most powerful prognosticator was the presence of $\mathrm{PH} . \dot{V}_{\mathrm{E}} / \dot{V}_{\mathrm{CO}_{2}}$ was tightly associated with $\mathrm{PH}$ (area under receiver operating characteristic curve: $0.94(0.89-0.98))$, thus it was not retained as an independent marker of mortality in multivariate analysis [112]. Several other studies with retrospective designs concerning IPF patients [123-125] or lung transplantation candidates with various ILDs $[126,127]$ showed that $\dot{V}_{\mathrm{E}} / \dot{V}_{\mathrm{CO}_{2}}$ was a mortality predictor at 1 or 3 years in univariate analysis, but not in final multivariate models. In a Japanese study of 41 IPF patients by Miкı et al. [123] (mean VC: $69 \pm 19 \%$; mean $D_{\mathrm{LCO}}$ : $44 \pm 15 \%$; mean peak $\dot{V}_{\mathrm{E}} / \dot{V}_{\mathrm{CO}_{2}}$ : $52 \pm 13$ ), peak $\dot{V}_{\mathrm{E}} / \dot{V}_{\mathrm{CO}_{2}}$ was the CPET variable most closely correlated with peak $\dot{V}_{\mathrm{O}_{2}}(r=-0.7 ; \mathrm{p}<0.0001)$, and was also correlated with $P_{\mathrm{aO}}$ slope, which was itself independently associated with mortality. Interestingly, in the work of WALLAERT et al. [124] with 63 IPF patients, among the numerous functional prognostic markers identified in univariate analysis, TLC $<65 \%$ and $\dot{V}_{\mathrm{E}} / \dot{V}_{\mathrm{O}_{2}}$ at $\mathrm{VTh}>45$ were independently predictive of 3-year transplant-free survival, that is to say another CPET variable very similar to $\dot{V}_{\mathrm{E}} / \dot{V}_{\mathrm{CO}_{2}}$.

Finally, $\dot{V}_{\mathrm{E}} / \dot{V}_{\mathrm{CO}_{2}}$ was found to be independently associated with mortality in two prospective monocentric series. The first one included 25 treatment-naive patients with mild-to-moderate IPF (mean FVC: 78 $\pm 22 \%$; mean $D_{\mathrm{LCO}}$ : $46 \pm 15 \%$; mean $\dot{V}_{\mathrm{E}}-\dot{V}_{\mathrm{CO}_{2}}$ slope: $40 \pm 14$ ) and slight-to-moderately severe dyspnoea. $\dot{V}_{\mathrm{E}}-\dot{V}_{\mathrm{CO}_{2}}$ slope (hazard ratio: 1.09 (1.04-1.15)) and peak $\dot{V}_{\mathrm{O}_{2}}$ (hazard ratio: $0.75(0.6-0.95)$ ) were the most potent predictors of survival [128]. Interestingly, $\dot{V}_{\mathrm{E}}-\dot{V}_{\mathrm{CO}_{2}}$ slope was the CPET variable best correlated with dyspnoea on the modified Medical Research Council (mMRC) scale $(r=0.73$; $p<0.001)$ [89], whereas the mMRC scale had previously been showed to independently predict mortality [129, 130]. In the second series, VAinshelboim et al. [38, 131] included 38 stable, but not incident, IPFs (median FVC: 68 (37-109); median $D_{\mathrm{LCO}}$ : 50 (23-91); median $\dot{V}_{\mathrm{E}}-\dot{V}_{\mathrm{CO}_{2}}$ slope: 43 (39-49)). Patients were subsequently randomised into two groups to assess the effects of a supervised 12-week exercise training program. As there was no difference in transplant-free survival at 40 months between both exercise training and control groups, patients were all analysed together for other prognostic factors. $\dot{V}_{\mathrm{E}} / \dot{V}_{\mathrm{CO}_{2}}$ at $\mathrm{VTh}>34, \dot{V}_{\mathrm{E}} / \dot{V}_{\mathrm{O}_{2}}$ nadir $>34$, peak $\dot{V}_{\mathrm{O}_{2}} \leqslant 13.8 \mathrm{~mL} \cdot \mathrm{kg}^{-1} \cdot \mathrm{min}^{-1}, \quad V_{\mathrm{T}}$ reserve $\leqslant 0.48 \mathrm{~L} \cdot$ breath $^{-1}$ and peak $\mathrm{WR}<62$ watts were associated with increased mortality or lung transplantation [131]. Exercise training significantly improved peak $\dot{V}_{\mathrm{O}_{2}}$ and $\dot{V}_{\mathrm{O}_{2}}$ at VTh, but not peak $\dot{V}_{\mathrm{E}} / \dot{V}_{\mathrm{CO}_{2}}$ [86]. This lack of effect of exercise training on $\dot{V}_{\mathrm{E}} / \dot{V}_{\mathrm{CO}_{2}}$ was also observed in another study with 21 worsening IPFs [132].

It is not very surprising that $\dot{V}_{\mathrm{E}} / \dot{V}_{\mathrm{CO}_{2}}$ seems to represent a reliable prognostic factor in ILDs, since it reflects the potential convergence of several pathophysiological mechanisms involved in disease progression and ultimately prognosis. Indeed, excessive hyperventilation at exercise may result from dynamic mechanical constraints secondary to lung restriction, exercise-induced hypoxaemia, pulmonary vasculopathy with increased $V_{\mathrm{D}}$ and other poorly understood peripheral factors. Incidentally, one weakness of some of the aforementioned studies is that pulmonary vasculopathy was not always assessed. A recent literature systematic review identified other confounding factors, including methodological heterogeneity and selective reporting bias [133]. Another limitation is that "baseline" CPET was actually often performed at different stages of the disease, since not only newly diagnosed ILDs were included. Moreover, very few studies have investigated the value of longitudinal data from subsequent CPETs.

Several studies have explored the links between $\mathrm{PH}$, exercise limitation and prognosis in ILDs. In these patients, associated PH was demonstrated to significantly impair maximal aerobic capacity [74, 110, 112 114], sometimes only when $\mathrm{PH}$ was classified as severe [111]. Additionally, $\dot{V}_{\mathrm{E}} / \dot{V}_{\mathrm{CO}_{2}}$ was found to correlate with dyspnoea during CPET (Borg scale) [110] and with PH severity, as assessed by sPAP measured by TTE, with correlation coefficients varying from 0.61 to 0.87 [110,111, 113]. In another series, peak $\dot{V}_{\mathrm{E}} / \dot{V}_{\mathrm{CO}_{2}}$ and peak $P_{\mathrm{ETCO}}$, were the two variables best correlated with mPAP measured during RHC $[114,134]$. In the monocentric work of VAN DER PLAs et al. [113], in which 38 prospectively enrolled IPF patients performed CPET and TTE, the optimal cut-off value for predicting a resting sPAP $\geqslant 40 \mathrm{mmHg}$ was a $\dot{V}_{\mathrm{E}} / \dot{V}_{\mathrm{CO}_{2}}$ at $\mathrm{VTh}>45$. This cut-off value also proved to be a good prognosis marker, since mean survival was $81.3 \pm 14.1$ months in the 24 patients with $\dot{V}_{\mathrm{E}} / \dot{V}_{\mathrm{CO}_{2}}$ at VTh $\leqslant 45$ versus $21 \pm 4.9$ months in the 14 patients with $\dot{V}_{\mathrm{E}} / \dot{V}_{\mathrm{CO}_{2}}$ at $\mathrm{VTh}>45$ (p=0.001). Conversely, it is of note that the cut-off value of $40 \mathrm{mmHg}$ for resting sPAP was not able to identify two groups with different prognosis ( $\mathrm{n}=27$ for $\mathrm{sPAP}<40 \mathrm{mmHg}$ and $\mathrm{n}=11$ for $\mathrm{SPAP} \geqslant 40 \mathrm{mmHg}$ ) [113]. 
Concerning SSc, an important German multicentric study by EwERT et al. [135] retrospectively analysed the outcome of 210 patients having performed CPET. Amongst them, 74 (35\%) had ILD on HRCT, rated as ILD limited to less than $20 \%$ of lung surface for 42 (20\%) or extensive ILD for 32 (15\%). Simultaneously, RHC was performed in 139 (66\%), leading to a diagnosis of PAH in 52 (25\%). In multivariate analysis, $\dot{V}_{\mathrm{E}}-\dot{V}_{\mathrm{CO}_{2}}$ slope (hazard ratio: 0.9 (0.83-0.98)) and peak $\dot{V}_{\mathrm{O}_{2}}$ (hazard ratio: 0.87 (0.81-0.94)) were significant predictive factors of long-term survival (median follow-up: 7.7 years), alongside age, FVC and Krogh factor ( $K_{\mathrm{CO}}$, i.e. $D_{\mathrm{LCO}}$ per alveolar volume). Optimal cut-off values with the highest discriminative power were 35 for $\dot{V}_{\mathrm{E}}-\dot{V}_{\mathrm{CO}_{2}}$ slope and $64.5 \%$ of predicted value for peak $\dot{V}_{\mathrm{O}_{2}}$ [135]. In another recent Italian monocentric study, Rosato et al. [136] prospectively included 45 SSc patients who subsequently performed baseline CPET, PFTs, TTE and HRCT (median lung surface with HRCT pattern of ILD on CALIPER analysis: 9.8\% (7.3-16.1); median FVC: 102\% (89-109); median $D_{\mathrm{LCO}}$ : 77\% (71-81); median $\dot{V}_{\mathrm{E}}-\dot{V}_{\mathrm{CO}_{2}}$ slope: 29 (28-32)). Then, PFTs and TTE were annually repeated during the 5-year follow-up. The study population was divided into two groups: 37 (82\%) with normal $\dot{V}_{\mathrm{E}}-\dot{V}_{\mathrm{CO}_{2}}$ slope at baseline and eight (18\%) with baseline ventilatory inefficiency as defined by $\dot{V}_{\mathrm{E}}-\dot{V}_{\mathrm{CO}_{2}}$ slope $\geqslant 35$. Baseline ventilatory inefficiency was a marker of ILD progression and pulmonary vasculopathy, with a greater decline of FVC (9.6\% (0.5-12.2) versus $2.4 \%(0.4-5.0) ; \mathrm{p}<0.05)$ and $D_{\text {LCO }}(9.2 \%$ (6.4-16.6) versus $2.3 \%(0.5-5.2) ; \mathrm{p}<0.01)$, and a greater raise in SPAP (7.8 mmHg (5.2-14.2) versus $-1.5 \mathrm{mmHg}(-1--3) ; \mathrm{p}<0.0001)$ during follow-up. Moreover, in multivariate analysis, $\dot{V}_{\mathrm{E}}-\dot{V}_{\mathrm{CO}_{2}}$ slope was independently associated with the onset of a new major vascular complication, namely digital ulcers, PAH and sclerodermal renal crisis (hazard ratio: 1.09 (1.02-1.2)). Lastly, $\dot{V}_{\mathrm{E}}-\dot{V}_{\mathrm{CO}_{2}}$ slope was the only significant independent prognostic factor of mortality from ILD at 5 years (hazard ratio: 1.27 (1.003-1.6)) and a $\dot{V}_{\mathrm{E}}-\dot{V}_{\mathrm{CO}_{2}}$ slope $\geqslant 35$ was a prognostic factor of all-cause mortality at 5 years [136]. The same team had previously showed that, in SSc patients without obvious cardiopulmonary involvement, $\dot{V}_{\mathrm{E}}-\dot{V}_{\mathrm{CO}_{2}}$ slope was a marker of vascular kidney damage [137] and was significantly correlated with global disease activity and severity, as assessed by Disease Activity Index and Disease Severity Index ( $r=0.59$ and 0.73 , respectively; both $\mathrm{p}<0.0001)$ [138]

\section{Conclusion}

ILDs are a devastating category of diseases, which can carry a poor prognosis in cases of progressive fibrosing pattern and/or associated PH. Exercise intolerance and exertional dyspnoea are key symptoms that contribute to curtailing and then avoiding physical activity, resulting in progressive deconditioning. The mechanisms of exercise intolerance in ILD patients are due to a combination of factors including altered pulmonary gas exchange, anomalies in pulmonary mechanics and cardiovascular function, as well as SMD. CPET can be a valuable tool to not only assist in diagnosis, determine the presence of comorbidities, objectively evaluate functional capacity, determine symptom severity, accurately prescribe exercise training and monitor disease progression or therapeutic response, but also generate valuable prognostic information and optimise the management of patients with ILD. Evidence concerning the clinical utility of ventilatory efficiency as a prognostic indicator in ILD is rapidly emerging and therefore promising.

Provenance: Commissioned article, peer reviewed.

Previous articles in this series: No. 1: Laveneziana P, Di Paolo M, Palange P. The clinical value of cardiopulmonary exercise testing in the modern era. Eur Respir Rev 2021; 30: 200187. No. 2: Agnostoni P, Sciomer S, Palermo P, et al. Minute ventilation/carbon dioxide production in chronic heart failure. Eur Respir Rev 2021; 30: 200141. No. 3: Watson M, lonescu MF, Sylvester K, et al. Minute ventilation/carbon dioxide production in patients with dysfunctional breathing. Eur Respir Rev 2021; 30: 200182. No. 4: Ward SA. Ventilation/carbon dioxide output relationships during exercise in health. Eur Respir Rev 2021; 30: 200160. No. 5: Collins SÉ, Phillips DB, Brotto AR, et al. Ventilatory efficiency in athletes, asthma and obesity. Eur Respir Rev 2021; 30: 200206. No. 6: Schaegger MR, Guenette JA, Jensen D. Impact of ageing and pregnancy on the minute ventilation/carbon dioxide production response to exercise. Eur Respir Rev 2021; 30: 200225. No. 7: Weatherald J, Philipenko B, Montani D, et al. Ventilatory efficiency in pulmonary vascular diseases. Eur Respir Rev 2021; 30: 200214. No. 8: Neder JA, Berton DC, Phillips DB, et al. Exertional ventilation/carbon dioxide output relationship in COPD: from physiological mechanisms to clinical applications. Eur Respir Rev 2021; 30: 200190. No. 9: Hager A. Minute ventilation/carbon dioxide production in congenital heart disease. Eur Respir Rev 2021; 30: 200178. No. 10: Laveneziana P, Palange P. Ventilatory efficiency and its clinical and prognostic value in adults with cystic fibrosis. Eur Respir Rev 2021; 30: 200395.

Conflict of interest: T. Gille reports personal fees from Boehringer Ingelheim and Roche, and other funding from Oxyvie (oxygen provider), LVL Medical (oxygen provider) and VITALAIRE (oxygen provider), outside the submitted 
work. P. Laveneziana reports personal fees from Novartis France, Chiesi France and Boehringer France, outside the submitted work.

\section{References}

$1 \quad$ King TE. Clinical advances in the diagnosis and therapy of the interstitial lung diseases. Am J Respir Crit Care Med 2005; 172: 268-279.

2 Margaritopoulos GA, Romagnoli M, Poletti V, et al. Recent advances in the pathogenesis and clinical evaluation of pulmonary fibrosis. Eur Respir Rev 2012; 21: 48-56.

3 Kokosi MA, Margaritopoulos GA, Wells AU. Personalised medicine in interstitial lung diseases: number 6 in the series 'personalised medicine in respiratory diseases' edited by Renaud Louis and Nicolas Roche. Eur Respir Rev 2018; 27: 170117.

4 O'Donnell DE, Chau LKL, Webb KA. Qualitative aspects of exertional dyspnea in patients with interstitial lung disease. J Appl Physiol 1998; 84: 2000-2009.

5 Sietsema KE, Sue DY, Stringer WW, et al. Wasserman \& Whipp's Principles of Exercise Testing and Interpretation. 6th edn. Philadelphia, Lippincott Williams \& Wilkins, 2020.

6 Palange $\mathrm{P}$, Ward SA, Carlsen K-H, et al. Recommendations on the use of exercise testing in clinical practice. Eur Respir J 2007; 29: 185-209.

7 Balady GJ, Arena R, Sietsema K, et al. Clinician's guide to cardiopulmonary exercise testing in adults. Circulation 2010; 122: 191-225.

8 Radtke T, Crook S, Kaltsakas G, et al. ERS statement on standardisation of cardiopulmonary exercise testing in chronic lung diseases. Eur Respir Rev 2019; 28: 180101.

9 Aguilaniu B, Wallaert B. From interpretation of cardiopulmonary exercise testing to medical decision. Rev Mal Respir 2013; 30: 498-515.

10 Ward S. Ventilation/carbon dioxide output relationships during exercise in health. Eur Respir Rev 2021; 30: 200160.

11 Jamnick NA, Pettitt RW, Granata C, et al. An examination and critique of current methods to determine exercise intensity. Sports Med 2020; 50: 1729-1756.

12 Puente-Maestu L, Palange P, Casaburi R, et al. Use of exercise testing in the evaluation of interventional efficacy: an official ERS statement. Eur Respir J 2016; 47: 429-460.

13 Weatherald J, Sattler C, Garcia G, et al. Ventilatory response to exercise in cardiopulmonary disease: the role of chemosensitivity and dead space. Eur Respir J 2018; 51: 1700860.

14 Phillips DB, Collins SÉ, Stickland MK. Measurement and interpretation of exercise ventilatory efficiency. Front Physiol 2020; 11: 659.

15 Laveneziana $\mathrm{P}$, Weatherald J. Pulmonary vascular disease and cardiopulmonary exercise testing. Front Physiol 2020; 11: 964.

16 Valeyre D, Duchemann B, Nunes H, et al. Interstitial lung diseases. In: Annesi-Maesano I, Lundbäck B, Viegi G, eds. ERS Monograph Respiratory Epidemiology. Sheffield, European Respiratory Society, 2014; pp. 79-87.

17 Sesé L, Khamis W, Jeny F, et al. Adult interstitial lung diseases and their epidemiology. Presse Med 2020; 49: 104023.

18 Duchemann B, Annesi-Maesano I, Jacobe de Naurois C, et al. Prevalence and incidence of interstitial lung diseases in a multi-ethnic county of Greater Paris. Eur Respir J 2017; 50: 1602419.

19 ATS/ERS. American Thoracic Society/European Respiratory Society international multidisciplinary consensus classification of the idiopathic interstitial pneumonias. Am J Respir Crit Care Med 2002; 165: 277-304.

20 Travis WD, Costabel U, Hansell DM, et al. An official American Thoracic Society/European Respiratory Society statement: update of the international multidisciplinary classification of the idiopathic interstitial pneumonias. Am J Respir Crit Care Med 2013; 188: 733-748.

21 Wells AU, Hirani N. Interstitial lung disease guideline. Thorax 2008; 63: v1-v58.

22 Jeny $\mathrm{F}$, Brillet $\mathrm{p}-\mathrm{Y}$, Kim $\mathrm{Y}-\mathrm{W}$, et al. The place of high-resolution computed tomography imaging in the investigation of interstitial lung disease. Expert Rev Respir Med 2019; 13: 79-94.

23 Raghu G, Remy-Jardin M, Myers JL, et al. Diagnosis of idiopathic pulmonary fibrosis. An Official ATS/ERS/ JRS/ALAT clinical practice guideline. Am J Respir Crit Care Med 2018; 198: e44-e68.

24 Cottin V, Wollin L, Fischer A, et al. Fibrosing interstitial lung diseases: knowns and unknowns. Eur Respir Rev 2019; 28: 180100.

25 George PM, Spagnolo P, Kreuter M, et al. Progressive fibrosing interstitial lung disease: clinical uncertainties, consensus recommendations, and research priorities. Lancet Respir Med 2020; 8: 925-934.

26 Flaherty KR, Wells AU, Cottin V, et al. Nintedanib in progressive fibrosing interstitial lung diseases. N Engl J Med 2019; 381: 1718-1727.

27 Wells AU, Flaherty KR, Brown KK, et al. Nintedanib in patients with progressive fibrosing interstitial lung diseases-subgroup analyses by interstitial lung disease diagnosis in the INBUILD trial: a randomised, double-blind, placebo-controlled, parallel-group trial. Lancet Respir Med 2020; 8: 453-460. 
O'Connell OJ, Egan JJ. The evaluation of disease severity/staging for prognosis. In: Costabel U, Crestani B, Wells AU, eds. ERS Monograph Idiopathic Pulmonary Fibrosis. Sheffield, European Respiratory Society, 2016; pp. 97-105.

Kolb M, Vašáková M. The natural history of progressive fibrosing interstitial lung diseases. Respir Res; 2019; 20: $1-8$.

Nunes $\mathrm{H}$, Uzunhan $\mathrm{Y}$, Gille $\mathrm{T}$, et al. Pulmonary hypertension complicating interstitial and granulomatous lung diseases. In: Humbert M, Souza R, Simonneau G, eds. Progress in Respiratory Research. Basel, S. Karger AG, 2012; pp. 178-198.

Panagiotou M, Church AC, Johnson MK, et al. Pulmonary vascular and cardiac impairment in interstitial lung disease. Eur Respir Rev 2017; 26: 160053.

Denison D, Al-Hillawi H, Turton C. Lung function in interstitial lung disease. Semin Respir Crit Care Med 1984; 6: 40-54.

Robertson HT. Clinical application of pulmonary function and exercise tests in the management of patients with interstitial lung disease. Semin Respir Crit Care Med 1994; 15: 1-9.

Baydur A. Physiology of ILD: recent developments in understanding and in clinical application. In: Sharma OP, ed. Interstitial Lung Diseases. New Delhi, Jaypee Brothers Medical Publishers; 2012; pp. 11-27.

Miguel-Reyes JL, Gochicoa-Rangel L, Pérez-Padilla R, et al. Functional respiratory assessment in interstitia lung disease. Rev Invest Clin 2015; 67: 5-14.

Wagner PD, Dantzker DR, Dueck R, et al. Distribution of ventilation-perfusion ratios in patients with interstitial lung disease. Chest 1976; 69: 256-257.

Keogh BA, Lakatos E, Price D, et al. Importance of the lower respiratory tract in oxygen transfer. Am Rev Respir Dis 1984; 129: S76-S80

Dunn TL, Watters LC, Hendrix C, et al. Gas exchange at a given degree of volume restriction is different in sarcoidosis and idiopathic pulmonary fibrosis. Am J Med 1988; 85: 221-224.

Agustí AGN, Roca J, Gea J, et al. Mechanisms of gas-exchange impairment in idiopathic pulmonary fibrosis. Am Rev Respir Dis 1991; 143: 219-225.

Nunes $\mathrm{H}$, Uzunhan $\mathrm{Y}$, Gille $\mathrm{T}$, et al. Imaging of sarcoidosis of the airways and lung parenchyma and correlation with lung function. Eur Respir J 2012; 40: 750-765.

Valeyre D, Bernaudin J-F, Jeny F, et al. Pulmonary sarcoidosis. Clin Chest Med 2015; 36: 631-641.

Kouranos V, Ward S, Kokosi MA, et al. Mixed ventilatory defects in pulmonary sarcoidosis: prevalence and clinical features. Chest 2020; 158: 2007-2014.

Wells AU, Margaritopoulos GA, Antoniou KM, et al. CPFE: distinctive and non-distinctive features. In: Costabel U, Crestani B, Wells AU, eds. ERS Monograph Idiopathic Pulmonary Fibrosis. Sheffield, European Respiratory Society, 2016; pp. 175-185.

Delobbe A, Perrault H, Maitre J, et al. Impaired exercise response in sarcoid patients with normal pulmonary function. Sarcoidosis Vasc Diffuse Lung Dis 2002; 19: 148-153.

Akkoca Ö, Celik G, Ulger F, et al. Exercise capacity in sarcoidosis. Study of 29 patients. Med Clin 2005; 124: 686-689.

Troy LK, Young IH, Lau EMT, et al. Exercise pathophysiology and the role of oxygen therapy in idiopathic interstitial pneumonia. Respirology 2016; 21: 1005-1014.

Aguilaniu B. CPET and interstitial pulmonary disease: what for and how to make the best use of it? La Lettre du Pneumologue 2016; 19: 16-20.

Bonini M, Fiorenzano G. Exertional dyspnoea in interstitial lung diseases: the clinical utility of cardiopulmonary exercise testing. Eur Respir Rev 2017; 26: 160099.

Molgat-Seon Y, Schaeffer MR, Ryerson CJ, et al. Exercise pathophysiology in interstitial lung disease. Clin Chest Med 2019; 40: 405-420.

Molgat-Seon Y, Schaeffer MR, Ryerson CJ, et al. Cardiopulmonary exercise testing in patients with interstitial lung disease. Front Physiol 2020; 11: 832.

Nathan SD, Basavaraj A, Reichner C, et al. Prevalence and impact of coronary artery disease in idiopathic pulmonary fibrosis. Respir Med 2010; 104: 1035-1041.

Broder M, Change E, Papoyan E, et al. Risk of cardiovascular comorbidities in patients with idiopathic pulmonary fibrosis: analysis of Medicare data. Eur Respir J 2016; 48: 14953-14958.

Gille T, Didier M, Boubaya M, et al. Obstructive sleep apnoea and related comorbidities in incident idiopathic pulmonary fibrosis. Eur Respir J 2017; 49: 1601934.

Davis R, Dixon C, Millar A, et al. A role for cardiopulmonary exercise testing in detecting physiological changes underlying health status in Idiopathic pulmonary fibrosis: a feasibility study. BMC Pulm Med 2021; 21: 147.

5 Jackson RM, Glassberg MK, Ramos CF, et al. Sildenafil therapy and exercise tolerance in idiopathic pulmonary fibrosis. Lung 2010; 188: 115-123.

Blanco I, Ribas J, Xaubet A, et al. Effects of inhaled nitric oxide at rest and during exercise in idiopathic pulmonary fibrosis. J Appl Physiol 2011; 110: 638-645. 
Schaeffer MR, Ryerson CJ, Ramsook AH, et al. Effects of hyperoxia on dyspnoea and exercise endurance in fibrotic interstitial lung disease. Eur Respir J 2017; 49: 1602494.

Tonelli R, Cocconcelli E, Lanini B, et al. Effectiveness of pulmonary rehabilitation in patients with interstitial lung disease of different etiology: a multicenter prospective study. BMC Pulm Med 2017; 17: 130.

Anderson SD, Bye PT. Exercise testing in the evaluation of diffuse interstitial lung disease. Aust NZ J Med 1984; 14: 762-768.

Marciniuk DD, Watts RE, Gallagher CG. Dead space loading and exercise limitation in patients with interstitial lung disease. Chest 1994; 105: 183-189.

Hansen JE, Wasserman K. Pathophysiology of activity limitation in patients with interstitial lung disease. Chest 1996; 109: 1566-1576.

Harris-Eze AO, Sridhar G, Clemens RE, et al. Role of hypoxemia and pulmonary mechanics in exercise limitation in interstitial lung disease. Am J Respir Crit Care Med 1996; 154: 994-1001.

Hughes JM, Lockwood DN, Jones HA, et al. $D_{\mathrm{LCO}} / \mathrm{Q}$ and diffusion limitation at rest and on exercise in patients with interstitial fibrosis. Respir Physiol 1991; 83: 155-166.

Renzi G, Milic-Emili J, Grassino AE. The pattern of breathing in diffuse lung fibrosis. Bull Eur Physiopathol Respir 1982; 18: 461-472.

Burdon JG, Killian KJ, Jones NL. Pattern of breathing during exercise in patients with interstitial lung disease. Thorax 1983; 38: 778-784.

DiMarco AF, Kelsen SG, Cherniack NS, et al. Occlusion pressure and breathing pattern in patients with interstitial lung disease. Am Rev Respir Dis 1983; 127: 425-430.

Faisal A, Alghamdi BJ, Ciavaglia CE, et al. Common mechanisms of dyspnea in chronic interstitial and obstructive lung disorders. Am J Respir Crit Care Med 2015; 193: 299-309.

Risk C, Epler GR, Gaensler EA. Exercise alveolar-arterial oxygen pressure difference in interstitial lung disease. Chest 1984; 85: 69-74.

Lamberto C, Nunes H, Le Toumelin P, et al. Membrane and capillary blood components of diffusion capacity of the lung for carbon monoxide in pulmonary sarcoidosis: relation to exercise gas exchange. Chest 2004; 125: 2061-2068.

Weitzenblum E, Ehrhart M, Rasaholinjanahary J, et al. Pulmonary hemodynamics in idiopathic pulmonary fibrosis and other interstitial pulmonary diseases. Respiration 1983; 44: 118-127.

Agustí AG, Roca J, Rodriguez-Roisin R, et al. Different patterns of gas exchange response to exercise in asbestosis and idiopathic pulmonary fibrosis. Eur Respir J 1988; 1: 510-516.

Baldi BG, Albuquerque ALP, Pimenta SP, et al. Exercise performance and dynamic hyperinflation in lymphangioleiomyomatosis. Am J Respir Crit Care Med 2012; 186: 341-348.

Rolland-Debord C, Fry S, Giovannelli J, et al. Physiologic determinants of exercise capacity in pulmonary Langerhans cell histiocytosis: a multidimensional analysis. PLOS ONE 2017; 12: e0170035.

Heiden GI, Sobral JB, Freitas CSG, et al. Mechanisms of exercise limitation and prevalence of pulmonary hypertension in pulmonary Langerhans cell histiocytosis. Chest 2020; 158: 2440-2448.

Dias OM, Baldi BG, Ferreira JG, et al. Mechanisms of exercise limitation in patients with chronic hypersensitivity pneumonitis. ERJ Open Res 2018; 4: 00043-02018.

Richter MJ, Voswinckel R, Tiede $\mathrm{H}$, et al. Dynamic hyperinflation during exercise in patients with precapillary pulmonary hypertension. Respir Med 2012; 106: 308-313.

Laveneziana P, Garcia G, Joureau B, et al. Dynamic respiratory mechanics and exertional dyspnoea in pulmonary arterial hypertension. Eur Respir J 2013; 41: 578-587.

O'Donnell DE, Ora J, Webb KA, et al. Mechanisms of activity-related dyspnea in pulmonary diseases. Respir Physiol Neurobiol 2009; 167: 116-132.

Laveneziana P. Qualitative aspects of exertional dyspnea in patients with restrictive lung disease. Multidiscip Respir Med 2010; 5: 211-215.

Schaeffer MR, Ryerson CJ, Ramsook AH, et al. Neurophysiological mechanisms of exertional dyspnoea in fibrotic interstitial lung disease. Eur Respir J 2018; 51: 1701726.

Cournoyer J, Ramos CF, Sturgill B, et al. Effects of 100\% oxygen during exercise in patients with interstitial lung disease. Respir Physiol Neurobiol 2020; 274: 103367.

Nishiyama O, Taniguchi H, Kondoh Y, et al. Quadriceps weakness is related to exercise capacity in idiopathic pulmonary fibrosis. Chest 2005; 127: 2028-2033.

Spruit MA, Thomeer MJ, Gosselink R, et al. Skeletal muscle weakness in patients with sarcoidosis and its relationship with exercise intolerance and reduced health status. Thorax 2005; 60: 32-38.

Watanabe F, Taniguchi H, Sakamoto K, et al. Quadriceps weakness contributes to exercise capacity in nonspecific interstitial pneumonia. Respir Med 2013; 107: 622-628.

Mendoza L, Gogali A, Shrikrishna D, et al. Quadriceps strength and endurance in fibrotic idiopathic interstitial pneumonia. Respirology 2014; 19: 138-143.

Vainshelboim B, Oliveira J, Fox BD, et al. Physiological profile and limitations in exercise in idiopathic pulmonary fibrosis. J Cardiopulm Rehabil Prev 2016; 36: 270-278. 
Kozu R, Senjyu H, Jenkins SC, et al. Differences in response to pulmonary rehabilitation in idiopathic pulmonary fibrosis and chronic obstructive pulmonary disease. Respiration 2011; 81: 196-205.

Marciniuk DD, Sridhar G, Clemens RE, et al. Lung volumes and expiratory flow limitation during exercise in interstitial lung disease. J Appl Physiol 1994; 77: 963-973.

Manali ED, Lyberopoulos P, Triantafillidou C, et al. MRC chronic dyspnea scale: relationships with cardiopulmonary exercise testing and 6-minute walk test in idiopathic pulmonary fibrosis patients: a prospective study. BMC Pulm Med 2010; 10: 32.

Walterspacher S, Schlager D, Walker DJ, et al. Respiratory muscle function in interstitial lung disease. Eur Respir J 2013; 42: 211-219.

Panagiotou M, Polychronopoulos V, Strange C. Respiratory and lower limb muscle function in interstitial lung disease. Chron Respir Dis 2016; 132: 162-172.

Marillier M, Bernard A-C, Verges S, et al. Oxygen supplementation during exercise improves leg muscle fatigue in chronic fibrotic interstitial lung disease. Thorax 2021; 76: 672-680.

Marcellis RGJ, Lenssen AF, de Vries J, et al. Reduced muscle strength, exercise intolerance and disabling symptoms in sarcoidosis. Curr Opin Pulm Med 2013; 19: 524-530.

Strookappe B, Saketkoo LA, Elfferich M, et al. Physical activity and training in sarcoidosis: review and experience-based recommendations. Expert Rev Respir Med 2016; 10: 1057-1068.

Miller A, Brown LK, Sloane MF, et al. Cardiorespiratory responses to incremental exercise in sarcoidosis patients with normal spirometry. Chest 1995; 107: 323-329.

Athos L, Mohler JG, Sharma OP. Exercise testing in the physiologic assessment of sarcoidosis. Ann NY Acad Sci 1986; 465: 491-501.

Medinger AE, Khouri S, Rohatgi PK. Sarcoidosis: the value of exercise testing. Chest 2001; 120: 93-101.

Wallaert B, Talleu C, Wemeau-Stervinou L, et al. Reduction of maximal oxygen uptake in sarcoidosis: relationship with disease severity. Respiration 2011; 82: 501-508.

Magrì D, Mariotta S, Banfi C, et al. Opposite behavior of plasma levels surfactant protein type B and receptor for advanced glycation end products in pulmonary sarcoidosis. Respir Med 2013; 107: 1617-1624.

Kallianos A, Zarogoulidis P, Ampatzoglou F, et al. Reduction of exercise capacity in sarcoidosis in relation to disease severity. Patient Prefer Adherence 2015; 9: 1179-1188.

Kisaka T, Cox TA, Dumitrescu D, et al. $\mathrm{CO}_{2}$ pulse and acid-base status during increasing work rate exercise in health and disease. Respir Physiol Neurobiol 2015; 218: 46-56.

Hagmeyer L, Herkenrath S, Anduleit N, et al. Cardiopulmonary exercise testing allows discrimination between idiopathic non-specific interstitial pneumonia and idiopathic pulmonary fibrosis in mild to moderate stages of the disease. Lung 2019; 197: 721-726.

de Martino M, Cobuccio R, Bruzzese D, et al. Exercise related ventilation dynamics and clinical correlates in patients with fibrotic idiopathic interstitial pneumonias. Sarcoidosis Vasc Diffuse Lung Dis 2016; 33: 157-165. Duvenkamp I, Bauer TT, Schmidt EW, et al. Submaximal spiroergometric stress study in patients with mixed dust pneumoconiosis. Pneumologie 1998; 52: 171-177.

Favre M-N, Roche N, Januel B, et al. Exercise test and evaluation of exertional dyspnoea in former coal miners. Rev Mal Respir 2002; 19: 315-322.

Petsonk EL, Stansbury RC, Beeckman-Wagner L-A, et al. Small airway dysfunction and abnormal exercise responses. A study in coal miners. Ann Am Thorac Soc 2016; 13: 1076-1080.

Schneider J, Arhelger R, Funk M. Spiroergometric parameters at maximal exercise testing assessed functional respiratory impairment in asbestos-induced fibrosis. Clin Respir J 2014; 8: 175-184.

Guazzi M, Adams V, Conraads V, et al. Clinical recommendations for cardiopulmonary exercise testing data assessment in specific patient populations. Eur Heart J 2012; 33: 2917-2927.

Weatherald J, Philipenko B, Montani D, et al. Ventilatory efficiency in pulmoary vascular disease. Eur Respir Rev 2021; 30: 200214.

Gläser S, Noga O, Koch B, et al. Impact of pulmonary hypertension on gas exchange and exercise capacity in patients with pulmonary fibrosis. Respir Med 2009; 103: 317-324. pulmonary hypertension. Respirology 2011; 16: 451-458.

Gläser S, Obst A, Koch B, et al. Pulmonary hypertension in patients with idiopathic pulmonary fibrosis - the predictive value of exercise capacity and gas exchange efficiency. PLOS ONE 2013; 8: e65643.

van der Plas MN, van Kan C, Blumenthal J, et al. Pulmonary vascular limitation to exercise and survival in idiopathic pulmonary fibrosis. Respirology 2014; 19: 269-275.

Armstrong HF, Thirapatarapong W, Dussault NE, et al. Distinguishing pulmonary hypertension in interstitial lung disease by ventilation and perfusion defects measured by cardiopulmonary exercise testing. Respiration 2013; 86: 407-413.

Degani-Costa LH, Levarge B, Digumarthy SR, et al. Pulmonary vascular response patterns during exercise in interstitial lung disease. Eur Respir J 2015; 46: 738-749. 
116 Dumitrescu D, Oudiz RJ, Karpouzas G, et al. Developing pulmonary vasculopathy in systemic sclerosis, detected with non-invasive cardiopulmonary exercise testing. PLOS ONE 2010; 5: e14293.

117 Boutou AK, Pitsiou GG, Siakka P, et al. Phenotyping exercise limitation in systemic sclerosis: the use of cardiopulmonary exercise testing. Respiration 2016; 91: 115-123.

118 Martis N, Queyrel-Moranne V, Launay D, et al. Limited exercise capacity in patients with systemic sclerosis: identifying contributing factors with cardiopulmonary exercise testing. J Rheumatol 2018; 45: 95-102.

119 Dumitrescu D, Nagel C, Kovacs G, et al. Cardiopulmonary exercise testing for detecting pulmonary arterial hypertension in systemic sclerosis. Heart 2017; 103: 774-782.

120 Coghlan JG, Denton CP, Grünig E, et al. Evidence-based detection of pulmonary arterial hypertension in systemic sclerosis: the DETECT study. Ann Rheum Dis 2014; 73: 1340-1349.

121 Santaniello A, Casella R, Vicenzi M, et al. Cardiopulmonary exercise testing in a combined screening approach to individuate pulmonary arterial hypertension in systemic sclerosis. Rheumatology 2020; 59: 1581-1586.

122 Fell CD, Liu LX, Motika C, et al. The prognostic value of cardiopulmonary exercise testing in idiopathic pulmonary fibrosis. Am J Respir Crit Care Med 2009; 179: 402-407.

123 Miki K, Maekura R, Hiraga T, et al. Impairments and prognostic factors for survival in patients with idiopathic pulmonary fibrosis. Respir Med 2003; 97: 482-490.

124 Wallaert B, Guetta A, Wemeau-Stervinou L, et al. Prognostic value of clinical exercise testing in idiopathic pulmonary fibrosis. Rev Mal Respir 2011; 28: 290-296.

125 King TE, Tooze JA, Schwarz Ml, et al. Predicting survival in idiopathic pulmonary fibrosis. Am J Respir Crit Care Med 2001; 164: 1171-1181.

126 Kawut SM, O'Shea MK, Bartels MN, et al. Exercise testing determines survival in patients with diffuse parenchymal lung disease evaluated for lung transplantation. Respir Med 2005; 99: 1431-1439.

127 Layton AM, Armstrong HF, Kim HP, et al. Cardiopulmonary exercise factors predict survival in patients with advanced interstitial lung disease referred for lung transplantation. Respir Med 2017; 126: 59-67.

128 Triantafillidou C, Manali E, Lyberopoulos P, et al. The role of cardiopulmonary exercise test in IPF prognosis. Pulm Med 2013; 2013: 514817

129 Manali ED, Stathopoulos GT, Kollintza A, et al. The Medical Research Council chronic dyspnea score predicts the survival of patients with idiopathic pulmonary fibrosis. Respir Med 2008; 102: 586-592.

130 Nishiyama $\mathrm{O}$, Taniguchi $\mathrm{H}$, Kondoh $\mathrm{Y}$, et al. A simple assessment of dyspnoea as a prognostic indicator in idiopathic pulmonary fibrosis. Eur Respir J 2010; 36: 1067-1072.

131 Vainshelboim B, Oliveira J, Fox BD, et al. The prognostic role of ventilatory inefficiency and exercise capacity in idiopathic pulmonary fibrosis. Respir Care 2016; 61: 1100-1109.

132 Jackson RM, Gómez-Marín OW, Ramos CF, et al. Exercise limitation in IPF patients: a randomized trial of pulmonary rehabilitation. Lung 2014; 192: 367-376.

133 Barratt SL, Davis R, Sharp C, et al. The prognostic value of cardiopulmonary exercise testing in interstitial lung disease: a systematic review. ERJ Open Res 2020; 6: 00027-2020.

134 Armstrong HF, Schulze PC, Bacchetta M, et al. Impact of pulmonary hypertension on exercise performance in patients with interstitial lung disease undergoing evaluation for lung transplantation. Respirology 2014; 19: 675-682.

135 Ewert R, Ittermann T, Habedank D, et al. Prognostic value of cardiopulmonary exercise testing in patients with systemic sclerosis. BMC Pulm Med 2019; 19: 230

136 Rosato E, Leodori G, Gigante A, et al. Reduced ventilatory efficiency during exercise predicts major vascular complications and mortality for interstitial lung disease in systemic sclerosis. Clin Exp Rheumatol 2020; 38: Suppl. 125, 85-91.

137 Gigante A, Romaniello A, Magrì D, et al. Correlation between intrarenal arterial stiffness and exercise tolerance in systemic sclerosis patients without renal and cardiopulmonary impairment: the role of the microvascular damage. Int J Cardiol 2015; 185: 122-124.

138 Rosato E, Romaniello A, Magrì D, et al. Exercise tolerance in systemic sclerosis patients without pulmonary impairment: correlation with clinical variables. Clin Exp Rheumatol 2014; 32: S-103-S-108. 